\title{
Whole-transcriptomic Profile of SK-MEL-3 Melanoma Cells Treated with the Histone Deacetylase Inhibitor: Trichostatin A
}

\author{
ELIZABETH A. MAZZIO and KARAM F.A. SOLIMAN
}

College of Pharmacy and Pharmaceutical Sciences, Florida A and M University, Tallahassee, FL, U.S.A.

\begin{abstract}
Background: Malignant melanoma cells can rapidly acquire phenotypic properties making them resistant to radiation and mainline chemotherapies such as decarbonize or kinase inhibitors that target RAS-proto-oncogene independent auto-activated mitogen-activated protein kinases (MAPK)/through dual specificity mitogen-activated protein kinase (MEK). Both drug resistance and inherent transition from melanocytic nevi to malignant melanoma involve the overexpression of histone deacetylases (HDACs) and a B-Raf proto-oncogene (BRAF) mutation. Materials and Methods: In this work, the effects of an HDAC class I and II inhibitor trichostatin A (TSA) on the whole transcriptome of SK-MEL-3 cells carrying a BRAF mutation was examined. Results: The data obtained show that TSA was an extremely potent HDAC inhibitor within SK-MEL-3 nuclear lysates, where TSA was then optimized for appropriate sub-lethal concentrations for in vitro testing. The whole-transcriptome profile shows a basic phenotype dominance in the SK-MEL-3 cell line for $i)$ synthesis of melanin, ii) phagosome acidification, iii) ATP hydrolysis-coupled proton pumps and iv) iron transport systems. While TSA did not affect the aforementioned major systems, it evoked a dramatic change to the transcriptome: reflected by a down-regulation of 810 transcripts and up-regulation of 833 , with fold-change from -15.27 to +31.1 $F C(p<0.00001)$. Largest differentials were found for the following transcripts: Up-regulated: Tetraspanin 13 (TSPAN13), serpin family $i$ member 1 (SERPINI1), ATPase $\mathrm{Na}+/ \mathrm{K}+$ transporting subunit beta 2 (ATP1B2), nicotinamide
\end{abstract}

This article is freely accessible online.

Correspondence to: Karam F.A. Soliman, Ph.D., College of Pharmacy \& Pharmaceutical Sciences, Florida A\&M University, 1520 ML King Blvd, Tallahassee, FL 32307, USA. E-mail: karam.soliman@famu.edu

Key Words: Melanoma cells, SK-MEL-3, transcriptomic profile, histone deacetylase inhibitor, trichostatin A, BRAF mutation, MAPK/MEK/BRAF oncogenic pathway, mitotic arrest. nucleotide adenylyl transferase 2 (NMNAT2), platelet-derived growth factor receptor-like (PDGFRL), cytochrome P450 family 1 subfamily A member 1 (CYP1A1), prostate androgenregulated mucin-like protein 1 (PARM1), secretogranin II (SCG2), SYT11 (synaptotagmin 11), rhophilin associated tail protein 1 like (ROPN1L); down-regulated: polypeptide $N$ acetylgalactosaminyltransferase 3 (GALNT3), carbonic anhydrase 14 (CAXIV), BCL2-related protein A1 (BCL2A1), protein kinase $C$ delta $(P R K C D)$, transient receptor potential cation channel subfamily $M$ member 1 (TRPM1), ubiquitin associated protein 1 like (UBAPIL), glutathione peroxidase 8 (GPX8), interleukin 16 (IL16), tumor protein p53 (TP53), and serpin family $H$ member 1 (SERPINH1). There was no change to any of the HDAC transcripts (class I, II and IV), the sirtuin HDAC family (1-6) or the BRAF proto-oncogene $v 599$ transcripts. However, the data showed that TSA downregulated influential transcripts that drive the BRAFextracellular signal-regulated kinase (ERK)1/2 oncogenic pathway (namely PRKCD and MYC proto-oncogene which negatively affected the cell-cycle distribution. Mitotic inhibition was corroborated by functional pathway analysis and flow cytometry confirming halt at the $G_{2}$ phase, occurring in the absence of toxicity. Conclusion: TSA does not alter HDAC transcripts nor BRAF itself, but down-regulates critical components of the MAPK/MEK/BRAF oncogenic pathway, initiating a mitotic arrest.

Aggressive melanomas are highly resistant to radiation and chemotherapy drugs such as dacarbazine, and account for fatal metastatic disease. B-Raf proto-oncogene (BRAF) somatic missense mutations within the kinase domain from a single substitution (V599E) account for a large majority of malignant cutaneous melanoma. (1) This mutation in melanoma is often found in the absence of an NRAS or KRAS mutationm, but renders autoactivation of the extracellular signal-regulated kinase (ERK)/mitogen-activated protein kinase (MAPK) cascade (2-4). Despite the attempted use of combination therapies including dual-specificity mitogen-activated protein kinase (MEK) inhibitors (e.g., trametinib, and cobimetinib) or BRAF inhibitors (e.g., vemurafenib and dabrafenib), there is 
a high degree of relapse (5-9). At the root of this pervasive resistance could be epigenetic changes that enable tumor cells to survive toxic insults, including those incurred from chemotherapy drugs. Some of the main epigenetic controlling elements are histone deacetylases (HDACs), which remove acetyl groups from histone tails and cores that drive nucleosome-constrictive gene silencing [reviewed in (10)]. The overexpression of HDACs in melanoma is a characteristic of acquired chemotherapeutic resistance (11) and drugs that inhibit HDACs such as panobinostat, and vorinostat prevent resistance to mainline drugs such as dacarbazine (12) and sensitize melanoma to BRAF/MEK inhibitors (13-16). HDAC inhibitors are believed to impair tumor-survival systems, in part, by reducing the expression of anti-apoptotic proteins [survivin, B-cell lymphoma-extra-large (BCL-XL), BCL2, myeloid cell leukemia sequence 1 protein (MCL1), X-linked inhibitor of apoptosis (XIAP)], while at the same time elevating expression of contributors to death such as BCL2like protein 4 (BAX), BCL2-associated X, apoptosis regulator (BAK) (17), death receptors (DR4 and DR5) (18), and the cell-cycle inhibitor (CKDN1A) (11). In this study, we evaluated the effects of trichostatin A (TSA), a potent class 1 and II HDAC inhibitor on the whole-transcriptome profile of SK-MEL-3 human melanoma cells, which carry the BRAF V599E mutation (1).

\section{Materials and Methods}

Cell culture media, phosphate-buffered saline, 96-well plates, pipette tips, fetal bovine serum (FBS), Alamar Blue and penicillin/streptomycin, as well as general reagents and supplies were all purchased from Sigma-Aldrich Co. (St. Louis, MO, USA) and VWR International (Radnor, PA, USA). SK-MEL-3 cells (ATCC HTB-69) and McCoy's 5a Medium Modified were obtained from the American Type Culture Collection (Rockville, MD, USA). All microarray equipment, reagents, and materials were purchased from Affymetrix/Thermo Fisher (Waltham, MA, USA).

HDAC activity. Nuclear lysates from untreated SK-MEL-3 cells were extracted using the EpiQuik ${ }^{\mathrm{TM}}$ Nuclear Extraction Kit (Epigentek; Farmingdale, NY, USA) and used for kinetic HDAC activity assays (ab156064; Abcam, Cambridge, MA, USA) according to the manufacturer's guidelines. The data were acquired using a Synergy HTX Multi-Mode Reader (BioTek, Winooski, VT, USA) with excitation at $355 / 40 \mathrm{~nm}$, emission at $460 / 40 \mathrm{~nm}$, optics: top, and gain: 37 . Data were acquired using Gen5 ${ }^{\mathrm{TM}}$ Data Analysis Software 2.06.10 (BioTek).

Cell culture. SK-MEL-3 (ATCC \# HTB-69) cells were cultured in $175 \mathrm{~cm} 3$ flasks using ATCCs-formulated McCoy's 5a Medium, supplemented with FBS (10\%) and $100 \mathrm{U} / \mathrm{ml}$ penicillin $\mathrm{G}$ sodium $/ 100 \mu \mathrm{g} / \mathrm{ml}$ streptomycin sulfate. Cells were grown at $37^{\circ} \mathrm{C}$ in $95 \%$ atmosphere $/ 5 \% \mathrm{CO}_{2}$ and sub-cultured every 3-5 days.

Cell viability assay. Alamar Blue cell assay was used to determine both 24-h viable cell count and 7-day cell proliferation. In this assay, viable cells reduce resazurin to resorufin, a compound detectable by fluorescence. Briefly, $96-$ well plates were seeded with cells at a density of $5 \times 10^{6}$ cells $/ \mathrm{mI}(24-\mathrm{h})$ or $0.5 \times 10^{6}$ cells $/ \mathrm{mI}(7-$ day). Cells were treated with or without TSA $(0.05-25 \mu \mathrm{M})$ and cultured at $37^{\circ} \mathrm{C}$, in $5 \% \mathrm{CO}_{2}$ atmosphere. Alamar Blue $(0.1 \mathrm{mg} / \mathrm{ml}$ in Hanks balanced salt solution [HBSS)] was added at $15 \% \mathrm{v} / \mathrm{v}$ to each well, and the plates were incubated for 6-8 h. Quantitative analysis of dye conversion was measured by Synergy ${ }^{\text {TM }}$ HTX MultiMode microplate reader (BioTek) at $550 \mathrm{~nm} / 580 \mathrm{~nm}$ (excitation/emission). The data were expressed as viable cell count as a percentage of untreated controls.

Fluorescence microscopy. Actin staining was conducted on untreated controls $v s$. cells treated with $1.56 \mu \mathrm{M}$ TSA for $24 \mathrm{~h}$. Staining was achieved using Alexa Fluor $488^{\circledR}$ phalloidin (Thermofisher, Norcross, GA, USA) and images were obtained using a fluorescent/inverted microscope, CCD camera and data acquisition by ToupTek View (ToupTek Photonics Co, Zhejiang, P.R. China).

Whole-transcriptome human 2.1ST arrays. After treatment $(1 \mu \mathrm{M}$ of TSA vs. untreated controls) for $24 \mathrm{~h}$, cells were washed three times in HBSS, followed by rapid freezing and storage at $-80^{\circ} \mathrm{C}$. Using the basic trizol/chloroform method for RNA extraction led to failure at several quality control points, where it was determined that melanin appeared to be bound to the RNA and directly inhibited polymerase chain reactions. Consequently, total RNA was isolated and purified using Aurum total RNA mini kit (Bio-Rad, Hercules, CA, USA) which was effective in removal of melanin. Next, the whole-transcriptome analysis was conducted using preparation and instructions according to the GeneChipTM WT PLUS Reagent Manual for the human ST 2.1 array chips (Affymetrix/ThermoFisher Scientific, Waltham, MA, USA). Briefly, RNA was synthesized to first-strand cDNA, secondstrand cDNA, followed by transcription to cRNA. cRNA was purified and assessed for yield, before synthesis of second-cycle singlestranded cDNA, hydrolysis of RNA and purification of second-cycle single-stranded cDNA. cDNA was then quantified for yield and equalized to $176 \mathrm{ng} / \mathrm{ml}$. Subsequently, cDNA was fragmented, labeled, and hybridized onto the arrays before being subject to fluidics and imaging using the Gene Atlas (Affymetrix/ThermoFisher Scientific, Waltham, MA, USA). The array data quality control and initial processing from CEL to CHP files were conducted using expression console, before data evaluation using the Affymetrix transcriptome analysis console. The data were reported as fold change of TSAtreated cells relative to the control group.

Flow cytometry for cell-cycle phase determination. Cells were plated in $75 \mathrm{~cm} 3$ flasks and cultured in low serum media (0.5\% FBS) for 24 $\mathrm{h}$ to synchronize cells in the cell cycle. After $24 \mathrm{~h}$, low serum media was removed, and high serum culture media (10\% FBS) was added before treatment with TSA. After $24 \mathrm{~h}$, cells were trypsinized, centrifuged and washed twice with assay buffer (Cayman Chemical, Ann Arbor, MI, USA), re-suspended to a density of 106 cells $/ \mathrm{ml}$ in a cell suspension, fixed and stored at $-20^{\circ} \mathrm{C}$. After $48 \mathrm{~h}$, the suspension was centrifuged at $300 \times g$ for $2 \mathrm{~min}$, the fixative was removed, and the pellet was re-suspended in $0.5 \mathrm{ml}$ of staining solution containing propidium iodide (PI) and RNase A (Cayman Chemical). The distribution of DNA in all cell-cycle phases was assayed in replicates, and the proportion of cells in each stage was determined within $2 \mathrm{~h}$ by using a FACS Calibur flow cytometer (BD Biosciences, San Jose, CA, USA). For each sample, a total of 20,000 individual events from the gated subpopulation were analyzed separately. CellQuest Pro software 
A

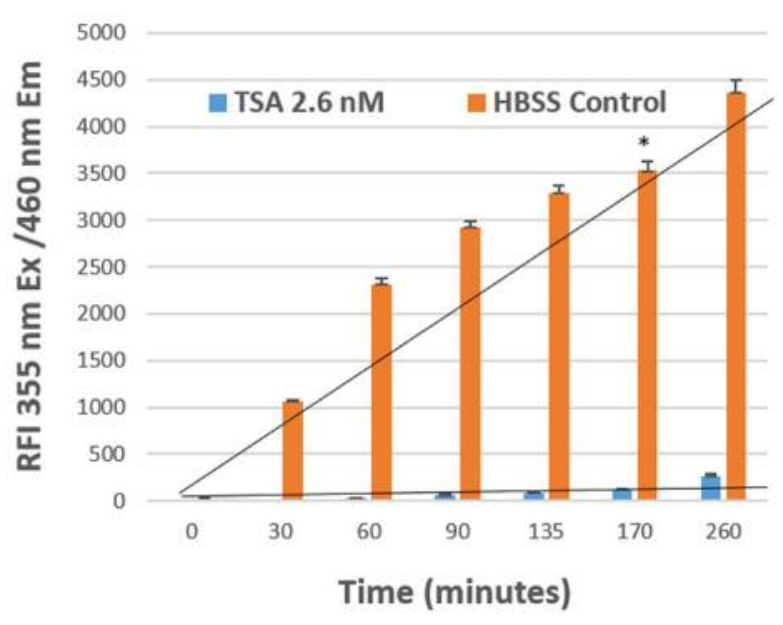

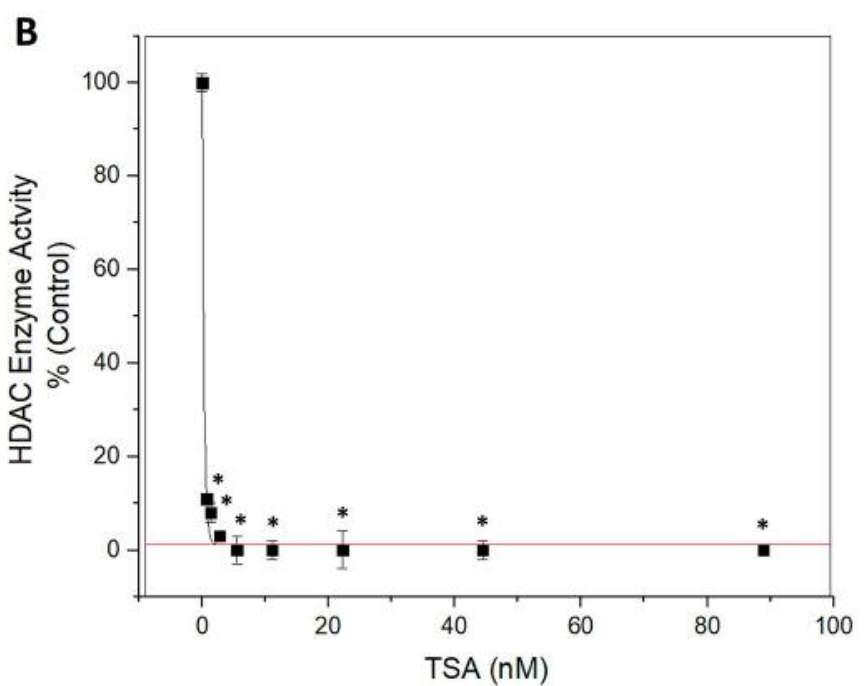

Figure 1. Histone deacetylase (HDAC) kinetics in nuclear lysate from SK-MEL-3 cells. A: The data represent the formation of de-acetylated peptides over $260 \mathrm{~min}$ in the absence and presence of $2.6 \mathrm{nM}$ trichostatin A (TSA). The data are expressed as the mean $\pm S$.E.M relative fluorescent units $(R F U)(n=4)$. Significance between the two groups was quantified with a two-way ANOVA, where the between-groups significance was $p<0.001$. B: SK-MEL-3 HDAC enzyme inhibition by TSA at 170 min of incubation. The data represent SK-MEL-3 HDAC activity as a percentage of the control and are presented as the mean \pm S.E.M $(n=4)$. The significance of the difference between the control and treatment groups was quantified by a one-way ANOVA and Tukey post-hoc test. *Significantly different from the control at $p<0.001$.

(BD Biosciences) was used for acquisition and analysis of the data, and the percentage of cells in each phase was determined using ModFit LT 3.2.1 Software (Verity Software House. Topsham, ME, USA).

Data analysis. Statistical analysis was performed using Graph Pad Prism (version 3.0; Graph Pad Software Inc. San Diego, CA, USA) with the significance of the difference between the groups assessed using a one-way ANOVA followed by Tukey post-hoc means comparison test or Student's $t$-test. Microarray data were analyzed using Affymetrix expression console, transcription analysis software - incorporating analysis from the Database for Annotation, Visualization and Integrated Discovery (DAVID ) v6.8 (19).

\section{Results}

TSA-mediated reduction of HDAC enzyme activity. Nuclear HDAC activity in SK-MEL-3 cells was confirmed by monitoring de-acetylated peptide formation as relative fluorescence, in the presence and absence of TSA $(2.6 \mathrm{nM})$ over time (Figure 1A). Significant signal/noise at $37^{\circ} \mathrm{C}$ was achieved at approximately $170 \mathrm{~min}$ of incubation, a time-point selected to generate a dose-response inhibition curve for TSA. The data show that the half maximal inhibitory concentration $\left(\mathrm{IC}_{50}\right)$ for TSA HDAC inhibition is less than $690 \mathrm{pM}$, which is extremely potent (Figure 1B). The SK-MEL3 HDAC nuclear lysate solution produced approximately $269 \mathrm{nM}$ of deacetylated peptide product at $170 \mathrm{~min}$ under assay conditions (Figure 2A), as quantified according to the deacetylated peptide standard curve. Figure $2 \mathrm{~B}$ represents the time course for the formation of a fluorometric product from the de-acetylated peptide product using the developer solution (lysl endopeptidase). TSA did not interfere with the product developer solution (Figure 2B), showing specificity only for the inhibition of HDAC (Figure 1).

Cytotoxicity of TSA. 24-hour toxicity of TSA in SK-MEL-3 cells was conducted where the data show a relatively highdose sub-lethal concentration yielding no observable effects on cell viability (Figure 3A) or structural morphology (Figure 3B) at $1.56 \mathrm{nM}$ of TSA. A 7-day proliferation study was also conducted at the same concentrations, where the data show TSA to exert cytostatic effects similar to the negative taxol control $(1 \mu \mathrm{M})$ (Figure 3A). These findings clearly show a predominant effect on the cell cycle, rather than apoptosis.

Such a high concentration of melanin in SK-MEL-3 cells completely blocked all in vitro transcription and PCR amplification processes using the standard trizol/chloroform technique of RNA extraction. Therefore, after $24 \mathrm{~h}$ of treatment with $1 \mu \mathrm{M}$ TSA, total RNA was extracted using steps essential to remove melanin from the nucleotide component using a spin-column technique. Basic array analysis on the control cells set showed a basic phenotype of SK-MEL-3 cells (Table I) with the inherent dominance of melanin synthesis, phagosome acidification, ATP hydrolysiscoupled proton and iron transport, where these systems remained largely unaffected by TSA. 

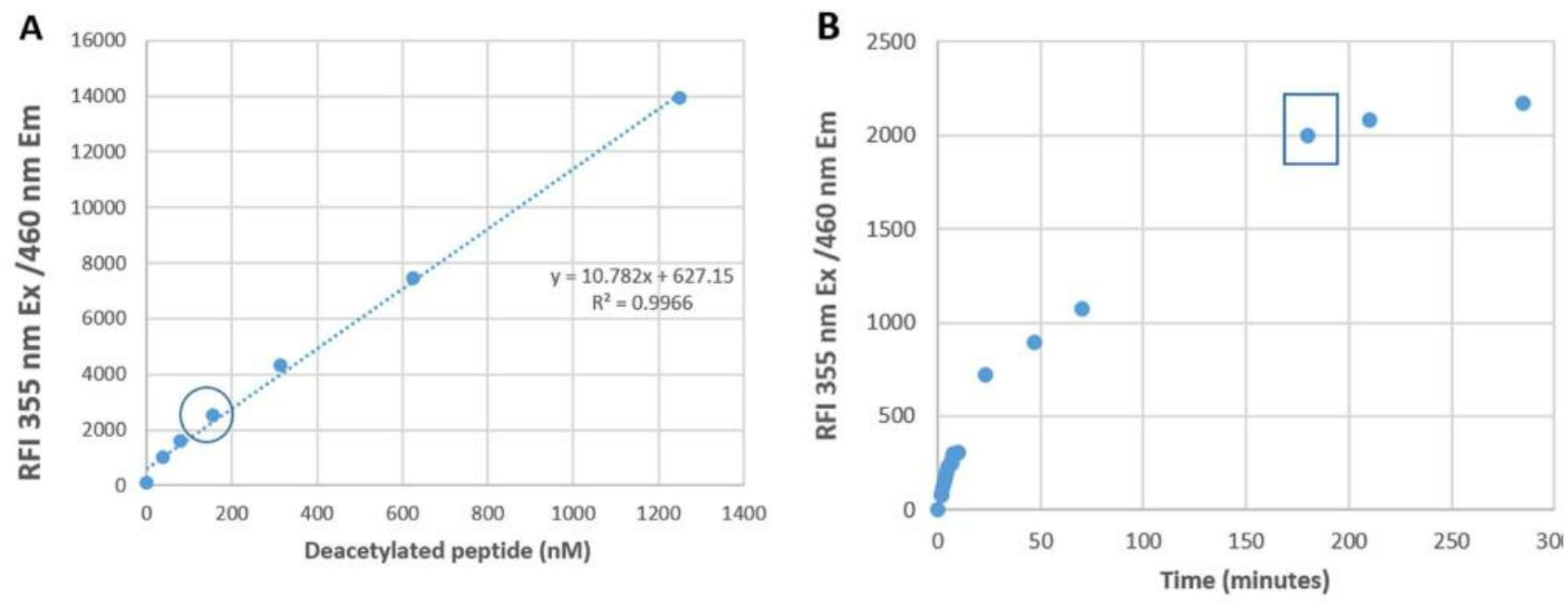

Figure 2. Histone deacetylase (HDAC) kinetics in nuclear lysate from SK-MEL-3 cells A: The de-acetylated peptide standard curve was generated using the endopeptidase fluorometric detection solution at $170 \mathrm{~min}$. Using this point of reference, the nuclear HDAC enzyme capacity of SK-MEL-3 cells for product formation was $156 \mathrm{nM}$ (denoted by encircled data point). B: Kinetics of HDAC secondary cascade reaction-involving product detection and fluoro-probe production. The data represent a single concentration of de-acetylated peptide (156 nM) cleaved through endopeptidase to form a fluorometric product. These findings show that HDAC substrate conversion to the product is a time-dependent process that parallels conversion of the HDAC substrate to product.
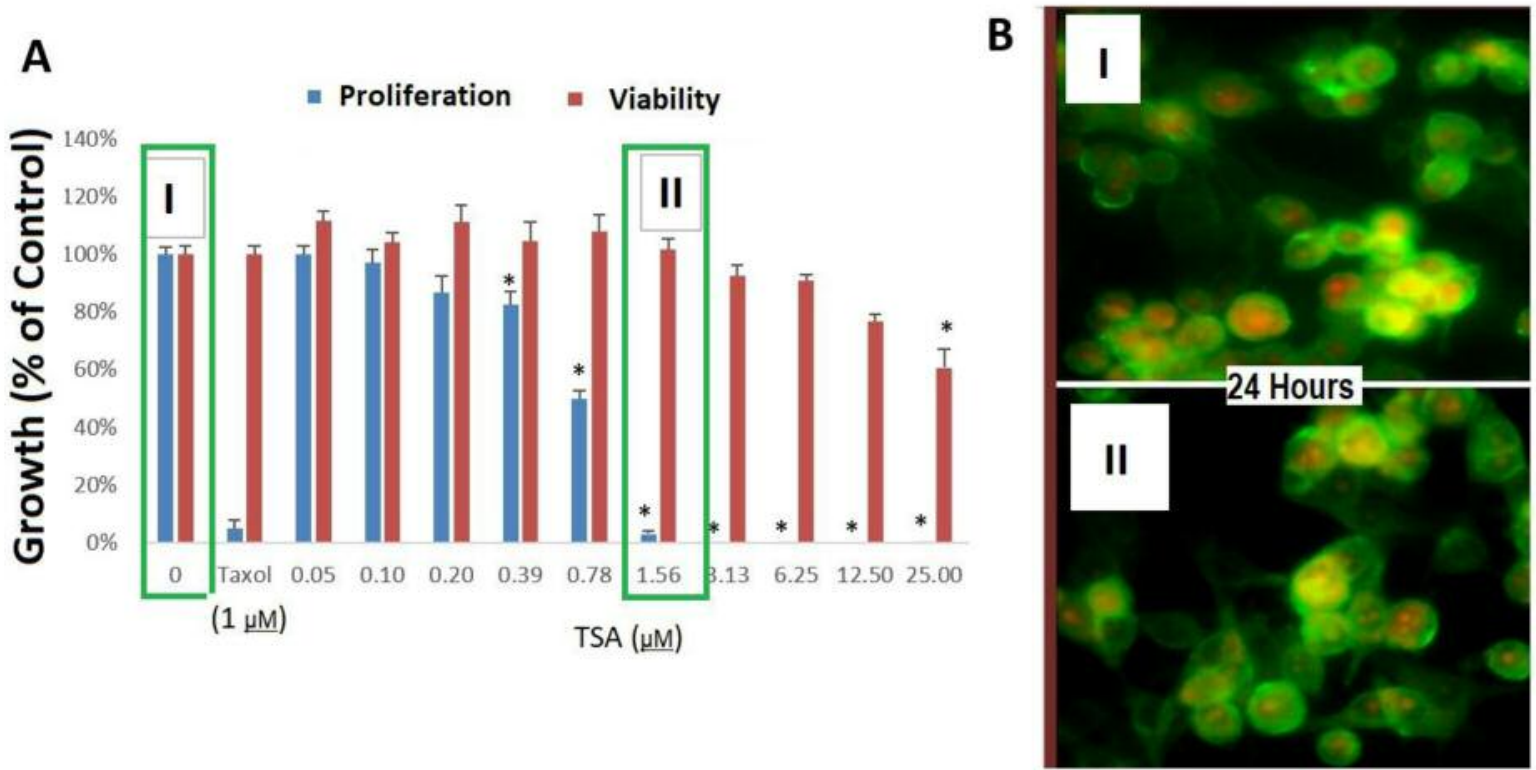

Figure 3. Effects of trichostatin A (TSA) on SK-MEL-3 melanoma cell growth. A: Viability (at 24 h) and cell proliferation (at 7 days) as a percentage that of the control and compared with the negative control taxol. Data are presented as the mean $\pm S E M(n=4)$. The significance of the difference between the control and treatment groups was quantified by a one-way ANOVA and Tukey post-hoc test. *Significantly different from the control at $p<0.05$. B: There were no observable differences in morphology or actin structure at the chosen concentration of TSA (1.56 $\mu M) v s$. controls.

In contrast, there were enormous changes to the wholetranscriptome evoked by TSA which is reflected by the volcano plot with highlighted gene symbols shown in Figure 4; most dominant changes are also presented in Table II, with data available for downloading at NCBI's Gene Expression Omnibus accessible through GEO Series accession number GSE104265 (https://www.ncbi.nlm.nih.gov/geo/query/acc. cgi? acc $=$ GSE104265). In brief, the information provides 
Table I. Global transcriptomic profile by dominant processes within SK-MEL-3 (ATCC $\left.{ }^{\circledR} H T B-69^{T M}\right)$ cells which were derived from a metastatic site (lymph node) from a 42-year-old Caucasian female with malignant melanoma. Data were acquired using the PANTHER (Protein ANalysis THrough Evolutionary Relationships) Classification System (61, 62).

\begin{tabular}{|c|c|c|c|c|c|}
\hline \multirow[t]{2}{*}{ GO biological process complete } & \multirow{2}{*}{$\begin{array}{l}\text { No. of genes } \\
\text { studied }\end{array}$} & \multicolumn{2}{|c|}{ Altered genes } & \multirow[t]{2}{*}{ Fold enrichment } & \multirow[t]{2}{*}{$p$-Value } \\
\hline & & No. found & No. expected & & \\
\hline Melanin biosynthetic process & 13 & 6 & 0.19 & 32.1 & $4.14 \mathrm{E}-04$ \\
\hline Melanin metabolic process & 14 & 6 & 0.2 & 29.8 & $6.39 \mathrm{E}-04$ \\
\hline Metabolic process & 9916 & 191 & 142.59 & 1.34 & $1.33 \mathrm{E}-04$ \\
\hline Organic substance metabolic process & 9468 & 187 & 136.15 & 1.37 & $2.62 \mathrm{E}-05$ \\
\hline Cellular metabolic process & 8976 & 180 & 129.07 & 1.39 & $2.43 \mathrm{E}-05$ \\
\hline Cellular process & 14970 & 271 & 215.26 & 1.26 & $5.08 \mathrm{E}-11$ \\
\hline Organic hydroxy compound biosynthetic process & 153 & 13 & 2.2 & 5.91 & 4.27E-03 \\
\hline Secondary metabolite biosynthetic process & 16 & 6 & 0.23 & 26.08 & $1.39 \mathrm{E}-03$ \\
\hline Phagosome acidification & 27 & 8 & 0.39 & 20.61 & 7.17E-05 \\
\hline Phagosome maturation & 40 & 8 & 0.58 & 13.91 & $1.42 \mathrm{E}-03$ \\
\hline Organelle organization & 3129 & 82 & 44.99 & 1.82 & $2.47 \mathrm{E}-04$ \\
\hline Cellular component organization & 5261 & 127 & 75.65 & 1.68 & $6.98 \mathrm{E}-07$ \\
\hline Cellular component organization or biogenesis & 5484 & 137 & 78.86 & 1.74 & $3.99 \mathrm{E}-09$ \\
\hline Intracellular $\mathrm{pH}$ reduction & 45 & 9 & 0.65 & 13.91 & $2.38 \mathrm{E}-04$ \\
\hline Regulation of intracellular $\mathrm{pH}$ & 92 & 12 & 1.32 & 9.07 & $1.28 \mathrm{E}-04$ \\
\hline Regulation of cellular $\mathrm{pH}$ & 96 & 12 & 1.38 & 8.69 & $2.03 \mathrm{E}-04$ \\
\hline Regulation of $\mathrm{pH}$ & 103 & 14 & 1.48 & 9.45 & $4.76 \mathrm{E}-06$ \\
\hline Monovalent inorganic cation homeostasis & 132 & 14 & 1.9 & 7.38 & $1.06 \mathrm{E}-04$ \\
\hline Cation homeostasis & 633 & 26 & 9.1 & 2.86 & $1.91 \mathrm{E}-02$ \\
\hline Inorganic ion homeostasis & 648 & 26 & 9.32 & 2.79 & $2.89 \mathrm{E}-02$ \\
\hline Cellular monovalent inorganic cation homeostasis & 110 & 12 & 1.58 & 7.59 & $8.71 \mathrm{E}-04$ \\
\hline Cellular cation homeostasis & 569 & 25 & 8.18 & 3.06 & $9.28 \mathrm{E}-03$ \\
\hline Cellular ion homeostasis & 584 & 25 & 8.4 & 2.98 & $1.47 \mathrm{E}-02$ \\
\hline ATP-coupled proton transport & 27 & 7 & 0.39 & 18.03 & $1.52 \mathrm{E}-03$ \\
\hline ATP hydrolysis-coupled cation transport & 58 & 9 & 0.83 & 10.79 & $1.98 \mathrm{E}-03$ \\
\hline Ion transport & 1312 & 42 & 18.87 & 2.23 & $1.00 \mathrm{E}-02$ \\
\hline Transport & 4382 & 163 & 63.01 & 2.59 & $1.38 \mathrm{E}-32$ \\
\hline Establishment of localization & 4491 & 164 & 64.58 & 2.54 & $7.05 \mathrm{E}-32$ \\
\hline Localization & 5459 & 174 & 78.5 & 2.22 & $3.67 \mathrm{E}-27$ \\
\hline Transmembrane transport & 1220 & 41 & 17.54 & 2.34 & $4.03 \mathrm{E}-03$ \\
\hline ATP hydrolysis-coupled ion transport & 70 & 9 & 1.01 & 8.94 & $9.28 \mathrm{E}-03$ \\
\hline Energy coupled proton transport, & 28 & 8 & 0.4 & 19.87 & $9.47 \mathrm{E}-05$ \\
\hline Hydrogen ion transmembrane transport & 116 & 13 & 1.67 & 7.79 & $1.87 \mathrm{E}-04$ \\
\hline Proton transport & 149 & 13 & 2.14 & 6.07 & $3.19 \mathrm{E}-03$ \\
\hline Hydrogen transport & 151 & 13 & 2.17 & 5.99 & $3.69 \mathrm{E}-03$ \\
\hline Transferrin transport & 36 & 8 & 0.52 & 15.45 & $6.41 \mathrm{E}-04$ \\
\hline Protein transport & 1358 & 71 & 19.53 & 3.64 & $1.42 \mathrm{E}-17$ \\
\hline Peptide transport & 1383 & 71 & 19.89 & 3.57 & $3.89 \mathrm{E}-17$ \\
\hline Amide transport & 1404 & 72 & 20.19 & 3.57 & $2.04 \mathrm{E}-17$ \\
\hline Nitrogen compound transport & 1667 & 83 & 23.97 & 3.46 & $4.83 \mathrm{E}-20$ \\
\hline Organic substance transport & 2030 & 93 & 29.19 & 3.19 & $1.35 \mathrm{E}-20$ \\
\hline Ferric iron transport & 39 & 8 & 0.56 & 14.27 & $1.17 \mathrm{E}-03$ \\
\hline Iron ion transport & 58 & 9 & 0.83 & 10.79 & $1.98 \mathrm{E}-03$ \\
\hline Transition metal ion transport & 110 & 11 & 1.58 & 6.95 & $6.90 \mathrm{E}-03$ \\
\hline Trivalent inorganic cation transport & 39 & 8 & 0.56 & 14.27 & $1.17 \mathrm{E}-03$ \\
\hline
\end{tabular}

analysis of 48,226 transcripts, of which 1,643 genes were differentially expressed: 833 genes were up-regulated, and 810 genes were down-regulated.

There was no differential change to HDACs (class I, II and IV) 1-12 (Figure 5) nor the sirtuin HDAC class (1-6) (data not shown), and similarly no change in transcript for mutated BRAF (data not shown).

Using the Affymetrix transcriptome console, major changes were found in three areas related to tumor control: MAPK signaling (Figure 6A), cell-cycle regulation (Figure 6B), with 


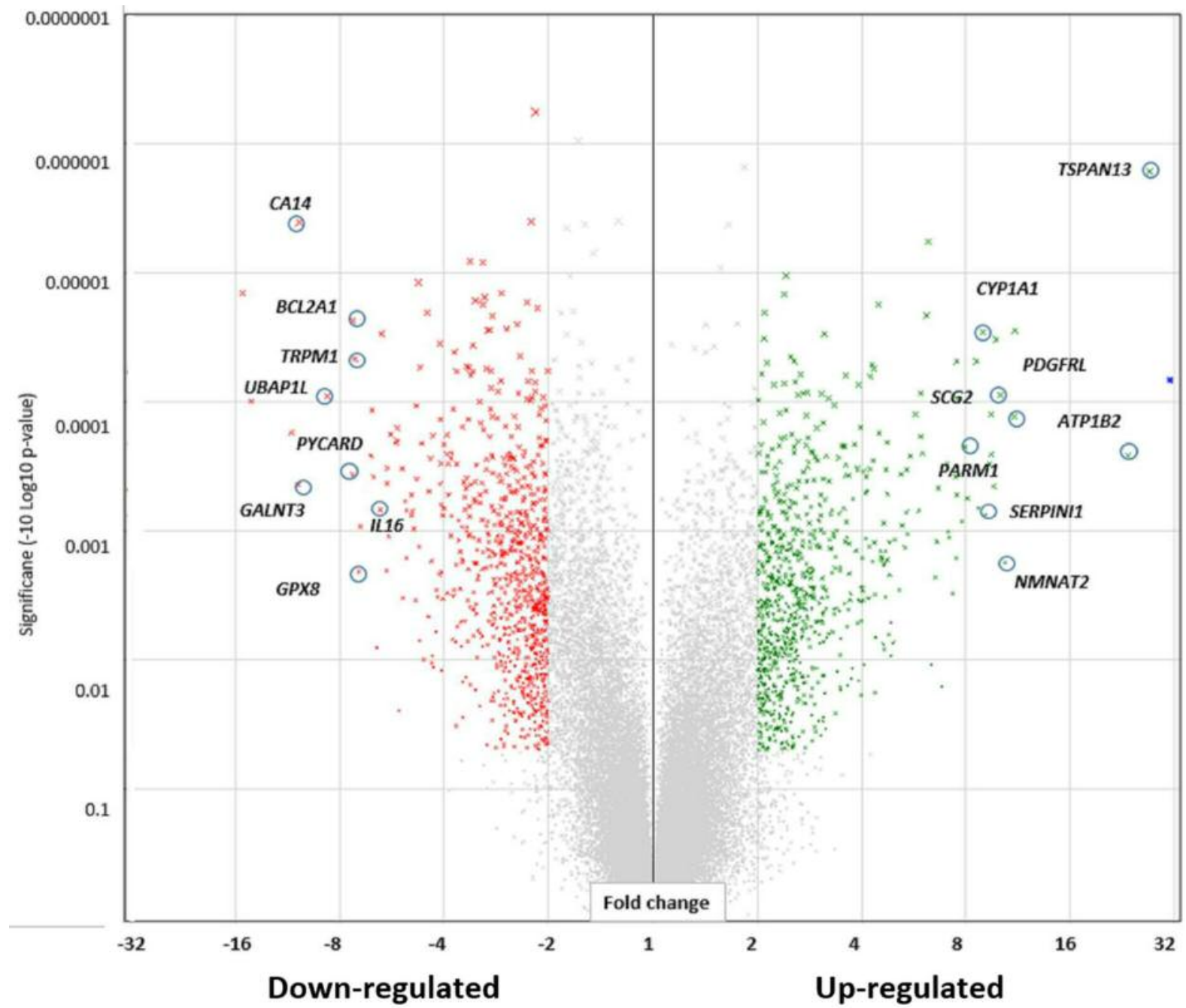

Figure 4. Whole-transcriptome changes in trichostatin A (TSA)-treated cells using the GeneChip ${ }^{T M}$ Human Gene 2.1 ST Array. The total number of genes tested was 48,226, of which 1,643 genes were differentially expressed: 833 were up-regulated, and 810 were down-regulated. These data are presented using a volcano plot (fold-change by significance). Down-regulated genes are shown in red and up-regulated genes in green; some of the most influential changes are highlighted. Genes are also listed in Table II. Down-regulated: Interleukin 16 (IL16), glutathione peroxidase (GPX8), ubiquitin associated protein 1-like (UBAPIL), PYD and CARD domain-containing (PYCARD), transient receptor potential cation channel (M1TRPM1), BCL2-related protein A1 (BCL2A1), carbonic anhydrase XIV (CA14), polypeptide N-acetylgalactosaminyltransferase 3 (GALNT3). Upregulated: tetraspanin (13 TSPAN13), serpin peptidase inhibitor, clade I (neuroserpin; SERPINI1), ATPase, Na+/K+ transporting, beta 2 polypeptide (ATP1B2), nicotinamide nucleotide adenylyl transferase 2 (NMNAT2), platelet-derived growth factor receptor-like (PDGFRL), cytochrome P450, family 1, subfamily A, polypeptide (1CYP1A1), prostate androgen-regulated mucin-like protein 1 (PARM1), secretogranin II (SCG2).

mitotic arrested also confirmed by flow cytometry (Figure 6C) and apoptosis (Figure 6D). In total, these findings demonstrate the global impact of inhibition of HDAC enzyme activity in SK-MEL3 malignant melanoma cells.

\section{Discussion}

Malignant melanoma can advance rapidly toward radiation and drug resistance, worsened by an inherent mutation of the
$B R A F$ gene which enables auto-activated RAF-independent oncogenic MAPK signaling. While there are dozens of $B R A F$ mutations, the most common is a substitution at nucleotide 1799 where a mutation leads to valine being replaced by glutamate at codon 599 or 600 . Treatment with inhibitors of BRAF (dabrafenib) or MEK (trametinib) can be initially effective, with time, there is often a high degree of relapse and development of resistance to chemotherapy agents (5-9). 


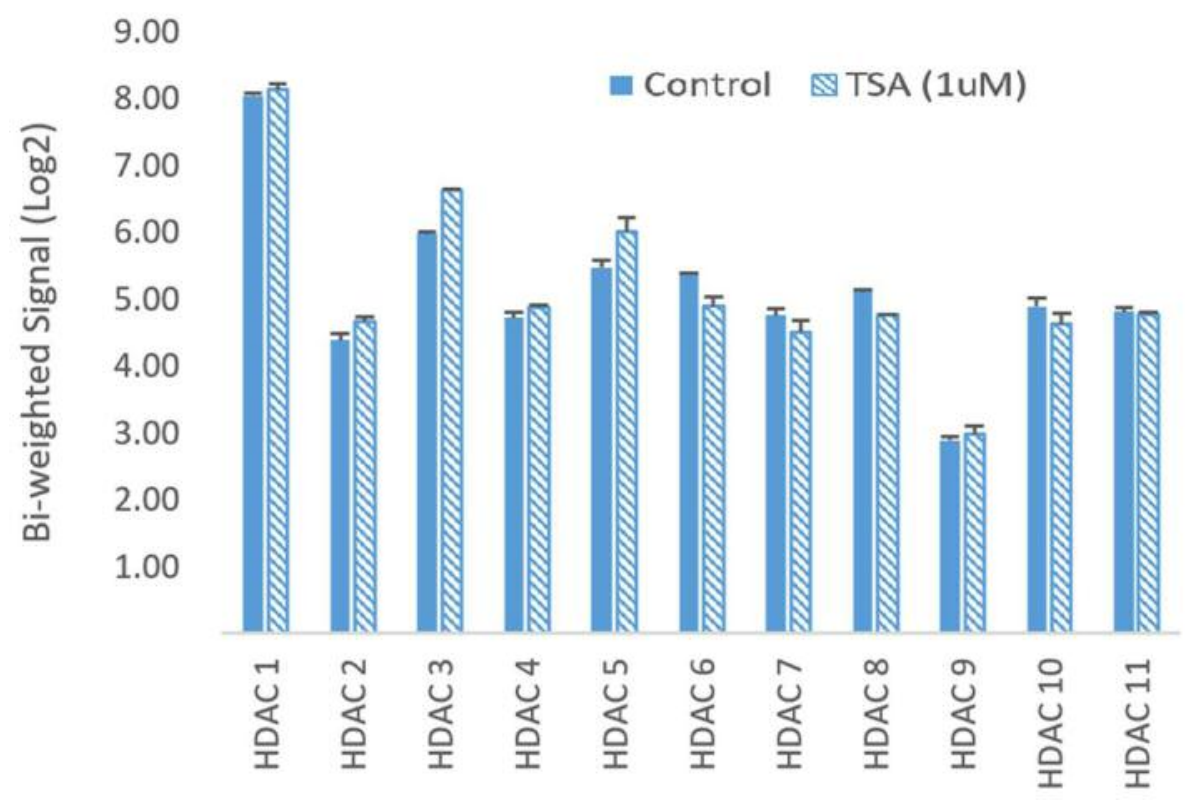

Figure 5. Effects of trichostatin A (TSA) (1 $\mu \mathrm{M})$ treatment for $24 \mathrm{~h}$ on histone deacetylase (HDAC) transcripts. The data represent the mean \pm SEM of the log2 bi-weighted signal from whole-transcriptome arrays. There were no significant differences between the two groups.

The epigenetic events which contribute to chemoresistant phenotypes might offer therapeutic targets for combination drug strategies. Moreover, while there are thousands of biological epigenetic controls, HDACs function as high-capacity removers of acetyl groups from histones to sustain silencing. Epigenetic drugs that inhibit one or more HDACs can broadly alter the transcriptome by reactivating either coding or non-coding functional mRNAs which contribute to antitumor phenotypes (11). In the case of melanoma, combined therapy with HDAC inhibitors reportedly prevents resistance to dacarbazine (12) and sensitize melanoma to BRAF and MEK inhibitors (13-16), but the mechanism for this is not well understood. In addition, while there is potential for the use of HDACS of diverse types (e.g., vorinostat, tubacin, sirtinol, vorinostat, suberoyl bis-hydroxamic acid) in the treatment of melanoma [review in (20)], HDAC inhibitors are broad-based, not specific to areas of the genome, and can elicit unwanted side-effects (11), such as hematological toxicity, fatigue and nausea (21).

Given the research community interest regarding the direct effects of HDAC inhibitors on $B R A F$-mutant melanoma, the goal of this investigation was to examine the efficacy of a known HDAC inhibitor (TSA) and its ability to alter the transcriptome in a $B R A F$-mutant melanoma cell model. While a discussion of the data in its entirety is not possible given the hundreds of changes to the transcriptome, furthermore there are changes to many transcripts for which little is known, we briefly discuss changes relevant to BRAF signaling.
MAPK signaling. BRAF signaling in tumor cells is overactive corresponding to abnormally high levels of phosphorylation signaling. The data in this work confirm that TSA neither alters the transcription of several HDAC classes or the expression of $B R A F$ itself. In contrast, TSA was found to reduce transcript levels of controlling elements of BRAF signaling, namely the upstream target protein kinase $\mathrm{C}$ delta $(P R K C D)$ and downstream target $M Y C$. $P R K C D$ is upstream of $B R A F$ and is highly overexpressed in a number of types of aggressive metastatic cancer (22) being an activator of phospho-ERK 1/2 signaling which can drive chemoresistant tumors (23-25), unbridled cell proliferation (22), phosphorylation of Ecadherin (which can perpetuate metastasis) (26) and in hypoxic tumors, up-regulate mRNA levels of hypoxiainducible factor 1 alpha $(\mathrm{HIF} 1 \alpha)(27)$ and glucose metabolism (28). The TSA-mediated reduction in $M Y C$ is one of the most compelling targets for treating chemoresistant melanoma. Down-regulation of MYC alone essentially blocks all four oncogenic pathways which lead to its up-regulation, namely NRAS proto-oncogene, GTPase (NRAS), BRAF, phosphatidylinositol-3-kinase and NOTCH (29), which are driving elements of MYC-directed tumor initiation, maintenance, and metastasis (30). Analysis of a large data pool of patient-derived $B R A F$-mutant melanoma showed that several pathways singly converge on activated overexpressed MYC, which manifests itself during relapse, resistance to BRAF/MEK inhibitors $(29,31,32)$ and transition of normal human skin to dysplastic nevi (33). The transformative 
Table II. Differentially expressed transcripts in trichostatin A (TSA)-treated vs. control-untreated SK-MEL-3 cells. The data are expressed as fold change (FC) and level of significance represented by a p-Value and false discovery rate (FDR) adjusted p-value.

\begin{tabular}{|c|c|c|c|c|c|c|}
\hline \multirow[t]{2}{*}{ Gene symbol } & \multirow[t]{2}{*}{ Description } & \multicolumn{3}{|c|}{$\begin{array}{l}\text { Mean bi-weighted. } \\
\text { signal (log2) }\end{array}$} & \multirow[t]{2}{*}{$p$-Value } & \multirow[t]{2}{*}{$\begin{array}{l}\text { FDR } p \\
\text { value }\end{array}$} \\
\hline & & Ctrl & TSA & $\begin{array}{c}\text { Fold- } \\
\text { change }\end{array}$ & & \\
\hline TSPAN13 & Tetraspanin 13 & 4.50 & 9.26 & 27.1 & $2.0 \mathrm{E}-06$ & 0.020 \\
\hline SERPINI1 & Serpin peptidase inhibitor, clade I (neuroserpin) & 3.42 & 7.98 & 23.5 & $2.6 \mathrm{E}-04$ & 0.046 \\
\hline ATP1B2 & ATPase, $\mathrm{Na}+/ \mathrm{K}+$ transporting, beta 2 polypeptide & 3.65 & 7.11 & 11.0 & $1.3 \mathrm{E}-04$ & 0.041 \\
\hline NMNAT2 & Nicotinamide nucleotide adenylyl transferase 2 & 3.04 & 6.41 & 10.4 & $1.8 \mathrm{E}-03$ & 0.072 \\
\hline PDGFRL & Platelet-derived growth factor receptor-like & 4.56 & 7.89 & 10.1 & $8.8 \mathrm{E}-05$ & 0.038 \\
\hline CYP1A1 & $\begin{array}{l}\text { Cytochrome } \mathrm{P} 450 \text {, family } 1 \text {, subfamily A, polypeptide } \\
1\end{array}$ & 3.60 & 6.88 & 9.8 & 3.3E-05 & 0.032 \\
\hline PARM1 & Prostate androgen-regulated mucin-like protein 1 & 4.46 & 7.73 & 9.6 & $4.5 \mathrm{E}-04$ & 0.050 \\
\hline ROPN1L & Rhoephilin associated tail protein 1-like & 2.80 & 6.04 & 9.5 & $1.3 \mathrm{E}-04$ & 0.041 \\
\hline SCG2 & Secretogranin II & 3.87 & 7.11 & 9.5 & $2.6 \mathrm{E}-04$ & 0.046 \\
\hline SYT11 & Synaptotagmin XI & 6.21 & 9.43 & 9.4 & $3.0 \mathrm{E}-04$ & 0.047 \\
\hline HIST1H2AG & Histone cluster 1, H2ag & 3.74 & 6.93 & 9.1 & $7.5 \mathrm{E}-04$ & 0.057 \\
\hline CTGF & Connective tissue growth factor & 3.57 & 6.73 & 9.0 & $2.9 \mathrm{E}-05$ & 0.030 \\
\hline SYN1 & Synapsin I & 3.85 & 6.97 & 8.7 & $6.7 \mathrm{E}-04$ & 0.056 \\
\hline DNER & Delta/NOTCH like EGF repeat containing & 5.52 & 8.62 & 8.6 & $4.8 \mathrm{E}-05$ & 0.034 \\
\hline FABP4 & Fatty acid binding protein 4 , adipocyte & 1.79 & 4.80 & 8.1 & $5.6 \mathrm{E}-04$ & 0.052 \\
\hline STC1 & Stanniocalcin 1 & 2.46 & 5.46 & 8.0 & $2.2 \mathrm{E}-04$ & 0.045 \\
\hline EFNB2 & Ephrin-B2 & 3.06 & 6.03 & 7.8 & $8.5 E-04$ & 0.060 \\
\hline$S R \times N 1$ & Sulfiredoxin 1 & 7.18 & 10.10 & 7.6 & $9.6 \mathrm{E}-05$ & 0.039 \\
\hline CYFIP2 & cytoplasmic FMR1 interacting protein 2 & 4.43 & 7.34 & 7.5 & $4.9 \mathrm{E}-05$ & 0.034 \\
\hline SLC7A11 & solute carrier family 7 & 6.85 & 9.75 & 7.5 & $5.3 E-04$ & 0.051 \\
\hline SEMA3D & Semaphorin 3D & 3.16 & 6.07 & 7.5 & $1.6 \mathrm{E}-03$ & 0.072 \\
\hline ELOVL4 & ELOVL fatty acid elongase 4 & 3.82 & 6.72 & 7.5 & $3.8 \mathrm{E}-04$ & 0.048 \\
\hline GUSBP3 & Glucuronidase, beta pseudogene 3 & 3.50 & 6.37 & 7.3 & $3.1 \mathrm{E}-03$ & 0.090 \\
\hline MIR2909 & MicroRNA 2909 & 6.36 & 9.21 & 7.2 & 1.1E-03 & 0.064 \\
\hline ID1 & Inhibitor of DNA binding 1 & 3.97 & 6.80 & 7.1 & $1.0 \mathrm{E}-03$ & 0.063 \\
\hline TMEM47 & Transmembrane protein 47 & 4.65 & 7.47 & 7.1 & $3.0 \mathrm{E}-04$ & 0.047 \\
\hline CXADR; BTG3 & Coxsackie virus and adenovirus receptor & 4.59 & 7.36 & 6.8 & $1.6 \mathrm{E}-02$ & 0.171 \\
\hline SPTLC3 & $\begin{array}{l}\text { Serine palmitoyltransferase, long chain base subunit } \\
3\end{array}$ & 4.88 & 7.61 & 6.6 & 4.7E-04 & 0.050 \\
\hline VGF & VGF nerve growth factor inducible & 4.75 & 7.47 & 6.6 & $1.2 \mathrm{E}-03$ & 0.066 \\
\hline EID3 & EP300 interacting inhibitor of differentiation 3 & 4.28 & 6.99 & 6.6 & $2.3 E-03$ & 0.080 \\
\hline BASP1 & Brain-abundant, membrane-attached signal protein 1 & 4.01 & 6.68 & 6.4 & $1.1 \mathrm{E}-02$ & 0.142 \\
\hline LOC730101 & uncharacterized LOC730101 & 4.51 & 7.14 & 6.2 & $6.0 \mathrm{E}-06$ & 0.025 \\
\hline ATP8A1 & ATPase, aminophospholipid transporter (APLT) & 3.60 & 6.22 & 6.2 & $2.1 \mathrm{E}-05$ & 0.029 \\
\hline CYR61 & Cysteine-rich, angiogenic inducer, 61 & 4.37 & 6.94 & 5.9 & $8.5 E-05$ & 0.038 \\
\hline PCDH9 & Protocadherin 9 & 3.33 & 5.90 & 5.9 & $1.9 E-04$ & 0.044 \\
\hline PRKAR2B & Protein kinase, cAMP-dependent, reg 2B & 5.08 & 7.63 & 5.9 & $7.0 \mathrm{E}-04$ & 0.056 \\
\hline EFNA3 & Ephrin-A3 & 3.75 & 6.27 & 5.7 & $1.3 \mathrm{E}-04$ & 0.041 \\
\hline HIST2H4B; $4 A$ & Histone cluster 2, $\mathrm{H} 4 \mathrm{~b}$; histone cluster 2, $\mathrm{H} 4 \mathrm{a}$ & 5.87 & 8.34 & 5.5 & 2.7E-04 & 0.046 \\
\hline ATP1B1 & ATPase, $\mathrm{Na}+/ \mathrm{K}+$ transporting, beta 1 polypeptide & 4.81 & 7.24 & 5.4 & $1.1 \mathrm{E}-03$ & 0.063 \\
\hline MYCT1 & MYC target 1 & 2.68 & 5.12 & 5.4 & $3.4 \mathrm{E}-04$ & 0.047 \\
\hline SSBP2 & Single-stranded DNA binding protein 2 & 4.46 & 6.89 & 5.4 & $7.2 \mathrm{E}-04$ & 0.056 \\
\hline STK17A & Serine/threonine kinase $17 a$ & 5.65 & 8.07 & 5.4 & $1.4 \mathrm{E}-03$ & 0.068 \\
\hline ANXA1 & Annexin A1 & 5.69 & 8.07 & 5.2 & 3.7E-04 & 0.048 \\
\hline PEG10 & Paternally expressed 10 & 7.65 & 10.01 & 5.1 & $2.9 \mathrm{E}-03$ & 0.087 \\
\hline HMOX1 & Heme oxygenase 1 & 6.13 & 8.45 & 5.0 & $1.2 \mathrm{E}-03$ & 0.065 \\
\hline
\end{tabular}


Table II. Continued

\begin{tabular}{|c|c|c|c|c|c|c|}
\hline SLC9A7 & Solute carrier family 9 , subfamily $\mathrm{A}$ (NHE7) & 2.61 & 4.92 & 4.9 & $7.4 \mathrm{E}-03$ & 0.122 \\
\hline LIFR & Leukemia inhibitory factor receptor alpha & 2.33 & 4.60 & 4.9 & $5.2 \mathrm{E}-03$ & 0.108 \\
\hline DHRS2 & Dehydrogenase/reductase (SDR family) member 2 & 2.61 & 4.89 & 4.8 & $9.3 E-03$ & 0.133 \\
\hline NLRP1 & NLR family, pyrin domain containing 1 & 5.98 & 8.25 & 4.8 & $1.2 \mathrm{E}-03$ & 0.066 \\
\hline RALGAPA2 & Ral GTPase activating protein, as2 & 5.89 & 8.15 & 4.8 & $2.2 \mathrm{E}-03$ & 0.079 \\
\hline$B 3 G A L T 1$ & $\begin{array}{l}\text { UDP-Gal: betaGIcNAc beta } 1,3- \\
\text { galactosyltransferase } 1\end{array}$ & 2.75 & 5.01 & 4.8 & $6.4 \mathrm{E}-03$ & 0.116 \\
\hline ST8SIA4 & ST8 alpha- $N$-acetyl-neuraminide sialyltransferase 4 & 4.90 & 7.15 & 4.8 & $5.2 \mathrm{E}-04$ & 0.051 \\
\hline PRDX1 & Peroxiredoxin 1 & 5.50 & 7.75 & 4.8 & 1.7E-03 & 0.072 \\
\hline ACTBL2 & Actin, beta-like 2 & 2.45 & 4.70 & 4.7 & $2.1 \mathrm{E}-04$ & 0.045 \\
\hline ENPP2 & Ectonucleotide pyrophosphatase/phosphodiesterase 2 & 6.91 & 9.15 & 4.7 & $3.4 \mathrm{E}-04$ & 0.047 \\
\hline PELI1 & Pellino E3 ubiquitin protein ligase 1 & 5.64 & 7.87 & 4.7 & $1.4 \mathrm{E}-03$ & 0.070 \\
\hline SMIM1OL2B & Small integral membrane protein 10 like $2 \mathrm{~B}$ & 2.76 & 4.98 & 4.7 & $3.3 E-03$ & 0.092 \\
\hline MAP2 & Microtubule associated protein 2 & 3.65 & 5.87 & 4.7 & $1.8 \mathrm{E}-03$ & 0.073 \\
\hline SLC41A2 & $\begin{array}{l}\text { Solute carrier family } 41 \text { (magnesium transporter), } \\
\text { member } 2\end{array}$ & 3.86 & 6.07 & 4.7 & $8.3 \mathrm{E}-03$ & 0.127 \\
\hline PAIP2B & Poly $(A)$ binding protein interacting protein $2 B$ & 5.01 & 7.22 & 4.6 & $1.9 \mathrm{E}-03$ & 0.074 \\
\hline UNC5D & Unc-5 netrin receptor $D$ & 2.90 & 5.11 & 4.6 & 8.7E-04 & 0.060 \\
\hline PRKAA2 & Protein kinase, AMP-activated, alpha 2 catalytic subunit & 4.15 & 6.36 & 4.6 & 7.6E-03 & 0.123 \\
\hline TTLL7 & Tubulin tyrosine ligase-like family member 7 & 5.18 & 7.37 & 4.6 & $1.6 \mathrm{E}-03$ & 0.072 \\
\hline USP53 & Ubiquitin specific peptidase 53 & 5.73 & 7.92 & 4.6 & $1.6 \mathrm{E}-03$ & 0.072 \\
\hline MGAT4A & $\begin{array}{l}\text { Mannosyl glycoprotein } n \text { - } \\
\text { acetylglucosaminyltransferase }\end{array}$ & 3.13 & 5.31 & 4.5 & $1.4 \mathrm{E}-03$ & 0.070 \\
\hline CRIM1 & $\begin{array}{l}\text { Cysteine rich transmembrane bmp regulator } 1 \\
\text { (chordin-like) }\end{array}$ & 4.40 & 6.57 & 4.5 & $1.7 \mathrm{E}-03$ & 0.072 \\
\hline SEL1L3 & Sel-1 suppressor of lin-12-like 3 (C. elegans) & 3.60 & 5.77 & 4.5 & $1.8 \mathrm{E}-04$ & 0.044 \\
\hline$S L C 2 A 3$ & Solute carrier family 2 & 3.93 & 6.09 & 4.5 & $1.8 \mathrm{E}-05$ & 0.029 \\
\hline MYEF2 & Myelin expression factor 2 & 4.15 & 6.27 & 4.4 & $3.2 \mathrm{E}-03$ & 0.090 \\
\hline HPSE & Heparanase & 3.62 & 5.74 & 4.4 & $1.2 \mathrm{E}-03$ & 0.066 \\
\hline $\mathrm{LIPH}$ & Lipase, member $\mathrm{h}$ & 2.39 & 4.50 & 4.3 & $5.6 \mathrm{E}-05$ & 0.034 \\
\hline DNAJB4 & DNAJ (hsp40) homolog, subfamily b, member 4 & 4.56 & 6.67 & 4.3 & $2.9 \mathrm{E}-04$ & 0.046 \\
\hline GCLM & Glutamate-cysteine ligase, modifier subunit & 6.12 & 8.23 & 4.3 & $1.7 \mathrm{E}-03$ & 0.072 \\
\hline$M \times D 1$ & Max dimerization protein 1 & 5.10 & 7.20 & 4.3 & $5.2 \mathrm{E}-05$ & 0.034 \\
\hline $\mathrm{BCO} 2$ & Beta-carotene oxygenase 2 & 3.07 & 5.15 & 4.2 & $3.3 E-04$ & 0.047 \\
\hline EYA1 & EYA transcriptional coactivator and phosphatase 1 & 4.89 & 6.96 & 4.2 & $1.3 \mathrm{E}-03$ & 0.068 \\
\hline $\mathrm{CDH} 19$ & Cadherin 19 , type 2 & 5.30 & 7.37 & 4.2 & $3.4 \mathrm{E}-03$ & 0.092 \\
\hline ENPP1 & Ectonucleotide pyrophosphatase/phosphodiesterase 1 & 7.61 & 9.66 & 4.1 & $3.8 \mathrm{E}-04$ & 0.048 \\
\hline$A R R D C 4$ & Arrestin domain containing 4 & 5.28 & 7.32 & 4.1 & $4.9 \mathrm{E}-04$ & 0.050 \\
\hline$A B C D 2$ & ATP binding cassette subfamily $\mathrm{d}$ member 2 & 2.26 & 4.30 & 4.1 & $5.1 \mathrm{E}-04$ & 0.051 \\
\hline EGR1 & Early growth response 1 & 3.73 & 5.77 & 4.1 & $1.2 \mathrm{E}-03$ & 0.065 \\
\hline FREM2 & Fras 1 related extracellular matrix protein 2 & 3.19 & 5.21 & 4.1 & $3.5 \mathrm{E}-04$ & 0.047 \\
\hline HIST1H2BD & Histone cluster $1, \mathrm{H} 2 \mathrm{bd}$ & 3.39 & 5.41 & 4.1 & $2.8 \mathrm{E}-03$ & 0.086 \\
\hline ARHGAP29 & Rho GTPase activating protein 29 & 3.25 & 5.27 & 4.0 & $3.5 \mathrm{E}-03$ & 0.093 \\
\hline MGAM2 & Maltase-glucoamylase 2 (putative) & 3.78 & 5.79 & 4.0 & $2.9 \mathrm{E}-03$ & 0.087 \\
\hline$A H R$ & Aryl hydrocarbon receptor & 8.63 & 10.64 & 4.0 & $1.6 \mathrm{E}-03$ & 0.072 \\
\hline NPTX2 & Neuronal pentraxin II & 4.71 & 6.71 & 4.0 & $5.0 \mathrm{E}-03$ & 0.107 \\
\hline MGAM2 & Maltase-glucoamylase 2 (putative) & 3.85 & 5.84 & 4.0 & $2.7 \mathrm{E}-03$ & 0.086 \\
\hline TCN1 & Transcobalamin I & 3.20 & 5.19 & 4.0 & $3.5 \mathrm{E}-03$ & 0.094 \\
\hline MGAM2 & Maltase-glucoamylase 2 (putative) & 2.81 & 4.80 & 4.0 & $1.9 \mathrm{E}-02$ & 0.185 \\
\hline PRKCD & Protein kinase $\mathrm{C}$, delta & 8.08 & 9.49 & -2.6 & $3.61 \mathrm{E}-04$ & 0.048 \\
\hline PARP3 & Poly (ADP-ribose) polymerase family member 3 & 7.11 & 5.11 & -4.0 & $2.1 \mathrm{E}-04$ & 0.045 \\
\hline АTOH8 & Atonal bHLH transcription factor 8 & 5.74 & 3.73 & -4.0 & $7.6 \mathrm{E}-04$ & 0.057 \\
\hline ACAT2 & Acetyl-CoA acetyltransferase 2 & 7.50 & 5.49 & -4.0 & $3.4 \mathrm{E}-03$ & 0.092 \\
\hline SNORD91B & Small nucleolar RNA, C/D box 91B & 6.36 & 4.34 & -4.1 & $1.2 \mathrm{E}-02$ & 0.149 \\
\hline TRIP6 & Thyroid hormone receptor interactor 6 & 7.80 & 5.77 & -4.1 & $6.3 \mathrm{E}-04$ & 0.055 \\
\hline TGFB1/1 & Transforming growth factor beta 1 induced transcript 1 & 7.86 & 5.84 & -4.1 & $2.1 \mathrm{E}-03$ & 0.078 \\
\hline
\end{tabular}


Table II. Continued

\begin{tabular}{|c|c|c|c|c|c|c|}
\hline MYC & $\begin{array}{l}\text { v-myc Avian myelocytomatosis viral oncogene } \\
\text { homolog }\end{array}$ & 8.50 & 6.47 & -4.1 & $1.4 \mathrm{E}-04$ & 0.041 \\
\hline PATZ1 & $\mathrm{POZ}$ (BTB) and AT hook containing zinc finger 1 & 5.63 & 3.60 & -4.1 & $4.3 \mathrm{E}-04$ & 0.049 \\
\hline ZC3H7B & Zinc finger $\mathrm{CCCH}$-type containing $7 \mathrm{~B}$ & 6.71 & 4.67 & -4.1 & 3.5E-05 & 0.032 \\
\hline KCNJ13 & Potassium channel, inwardly rectifying subfamily J & 6.10 & 4.06 & -4.1 & $2.2 \mathrm{E}-03$ & 0.079 \\
\hline IGF2BP1 & Insulin-like growth factor 2 mRNA binding protein 1 & 6.59 & 4.54 & -4.2 & 3.3E-03 & 0.092 \\
\hline RFTN2 & RAFTLIN family member 2 & 5.98 & 3.90 & -4.2 & $2.9 \mathrm{E}-03$ & 0.087 \\
\hline PRKG2 & protein kinase, cGMP-dependent, type II & 6.26 & 4.18 & -4.2 & $6.1 \mathrm{E}-03$ & 0.114 \\
\hline PHF19 & PHD finger protein 19 & 6.29 & 4.19 & -4.3 & $1.1 \mathrm{E}-02$ & 0.145 \\
\hline ARHGAP31 & Rho GTPase activating protein 31 & 6.01 & 3.90 & -4.3 & $1.8 \mathrm{E}-04$ & 0.044 \\
\hline MMP14 & Matrix metallopeptidase 14 (membrane-inserted) & 8.69 & 6.57 & -4.4 & $2.8 \mathrm{E}-04$ & 0.046 \\
\hline SLC45A2 & Solute carrier family 45, member 2 & 9.67 & 7.52 & -4.4 & $4.9 \mathrm{E}-04$ & 0.050 \\
\hline MIR3142 & microRNA 3142 & 6.19 & 4.04 & -4.4 & 4.7E-03 & 0.103 \\
\hline MEPCE & Methylphosphate capping enzyme & 7.15 & 4.99 & -4.5 & 2.0E-05 & 0.029 \\
\hline NFATC2 & Nuclear factor of activated T-cells & 8.94 & 6.71 & -4.7 & $5.4 \mathrm{E}-05$ & 0.034 \\
\hline CXCL1 & $\begin{array}{l}\text { CXC ligand } 1 \text { (melanoma growth stimulating activity, } \\
\text { alpha) }\end{array}$ & 6.05 & 3.81 & -4.7 & $1.2 \mathrm{E}-05$ & 0.029 \\
\hline TEAD2 & TEA domain family member 2 & 5.62 & 3.38 & -4.7 & $1.3 \mathrm{E}-03$ & 0.068 \\
\hline SLC24A5 & Solute carrier family 24 , member 5 & 9.18 & 6.92 & -4.8 & $1.1 \mathrm{E}-04$ & 0.039 \\
\hline GYPC & Glycophorin C (Gerbich blood group) & 6.56 & 4.30 & -4.8 & $4.0 \mathrm{E}-04$ & 0.048 \\
\hline PER3 & Period circadian clock 3 & 6.22 & 3.93 & -4.9 & 9.7E-04 & 0.063 \\
\hline ANGPTL2 & Angiopoietin like 2 & 7.23 & 4.93 & -4.9 & 7.1E-04 & 0.056 \\
\hline OAS2 & 2-5-Oligoadenylate synthetase 2 & 6.66 & 4.35 & -5.0 & $5.3 \mathrm{E}-04$ & 0.051 \\
\hline HAS2 & Hyaluronan synthase 2 & 6.72 & 4.41 & -5.0 & 7.6E-04 & 0.057 \\
\hline ZBTB2 & Zinc finger and BTB domain containing 2 & 6.30 & 3.94 & -5.1 & $6.9 \mathrm{E}-04$ & 0.056 \\
\hline LG/3 & Leucine-rich repeat LGI family, member 3 & 9.08 & 6.71 & -5.2 & $5.9 \mathrm{E}-04$ & 0.053 \\
\hline HIST1H2BM & Histone cluster $1, \mathrm{H} 2 \mathrm{bm}$ & 7.25 & 4.85 & -5.3 & $3.3 \mathrm{E}-03$ & 0.092 \\
\hline UCN2; PFKFB4 & Urocortin 2 & 7.58 & 5.17 & -5.3 & 3.3E-04 & 0.047 \\
\hline SNORA72 & Small nucleolar RNA, H/ACA box 72 & 5.30 & 2.87 & -5.4 & $2.5 \mathrm{E}-02$ & 0.209 \\
\hline LCP2 & Lymphocyte cytosolic protein 2 & 7.46 & 5.00 & -5.5 & $2.0 \mathrm{E}-04$ & 0.044 \\
\hline$S P R$ & Sepiapterin reductase & 7.77 & 5.31 & -5.5 & 2.1E-04 & 0.045 \\
\hline APOBEC $3 C$ & $\begin{array}{l}\text { Apolipoprotein B mRNA editing enzyme, catalytic } \\
\text { polypeptide-like } 3 C\end{array}$ & 9.26 & 6.75 & -5.7 & $1.8 \mathrm{E}-04$ & 0.044 \\
\hline MIR4534 & MicroRNA 4534 & 7.40 & 4.87 & -5.8 & $1.1 \mathrm{E}-03$ & 0.064 \\
\hline FRG2DP & FSHD region gene 2 family, member $D$, pseudogene & 7.72 & 5.18 & -5.8 & 3.3E-04 & 0.047 \\
\hline MIR146A & MicroRNA 146a & 7.81 & 5.27 & -5.8 & 4.3E-04 & 0.049 \\
\hline TPCN2 & Two pore segment channels 2 & 8.86 & 6.31 & -5.9 & $2.0 \mathrm{E}-03$ & 0.077 \\
\hline FXYD3 & FXYD domain containing ion transport regulator 3 & 6.98 & 4.38 & -6.1 & 3.0E-05 & 0.030 \\
\hline SERPINH1 & Serpin peptidase inhibitor, clade $\mathrm{H}$ & 7.66 & 5.05 & -6.1 & $6.8 \mathrm{E}-04$ & 0.056 \\
\hline LOC285000 & Uncharacterized LOC285000 & 5.93 & 3.26 & -6.4 & $3.8 \mathrm{E}-04$ & 0.048 \\
\hline TP53 & Tumor protein p53 & 8.64 & 5.95 & -6.5 & $1.2 \mathrm{E}-04$ & 0.040 \\
\hline IL16 & Interleukin 16 & 6.60 & 3.90 & -6.5 & 2.6E-04 & 0.046 \\
\hline SNORA75 & Small nucleolar RNA, H/ACA box 75 & 7.98 & 5.17 & -7.0 & $9.4 \mathrm{E}-04$ & 0.062 \\
\hline GPX8 & Glutathione peroxidase 8 (putative) & 6.24 & 3.43 & -7.1 & 2.1E-03 & 0.078 \\
\hline UBAP1L & Ubiquitin-associated protein 1 like & 6.86 & 4.00 & -7.2 & 4.7E-05 & 0.034 \\
\hline PYCARD & PYD and CARD domain containing & 7.98 & 5.10 & -7.3 & 3.7E-04 & 0.048 \\
\hline TRPM1 & Transient receptor potential cation channel, M1 & 6.61 & 3.73 & -7.4 & $2.4 \mathrm{E}-05$ & 0.030 \\
\hline BCL2A1 & BCL2-related protein A1 & 8.62 & 5.50 & -8.7 & $9.0 \mathrm{E}-05$ & 0.038 \\
\hline CA14 & Carbonic anhydrase XIV & 8.19 & 4.80 & -10.5 & 4.0E-06 & 0.022 \\
\hline GALNT3 & Polypeptide $N$-acetylgalactosan & 6.85 & 3.44 & -10.6 & 4.4E-04 & 0.050 \\
\hline LINC00681 & Long intergenic non-protein coding RNA 681 & 8.77 & 4.84 & -15.3 & $1.4 \mathrm{E}-05$ & 0.029 \\
\hline
\end{tabular}


resistance of $B R A F$-mutant melanoma is reversible by knockdown or drug inhibition of $M Y C$ alone (29, 34-36).

Mitosis. Functional pathway analysis shows that TSA reduced several controls over key cell cycle-related transcripts including: ataxia telangiectasia mutated serine/threonine kinase $(A T M)$ that is activated by DNA damage during radiation, responsible for activation of checkpoint cell-cycle controlling kinase 2 (CHK2), which can further prevent cells from entering mitosis at the $\mathrm{G}_{2} / \mathrm{M}$ phase, all of which is believed to maintain stability of the genome (37-39). While it is uncertain what role this would have in cancer growth, a loss of function of ATM is believed to render greater genomic instability, which in theory would augment effects of radio-or chemotherapies. TSA also evoked a loss in the F-box protein S-phase kinase-associated protein 2 (SKP2) which is part of the SKP1-Cullin1-F-box protein ubiquitin ligase complex responsible for the degradation of cyclin-dependent kinase inhibitor p21 (CIP1/WAF1) which halts the cycle at the S-phase (40). A loss of SKP2 would be detrimental in several aspects such as initiating degradation of tumor suppressor p27 and KIP1 accumulation of p21, which causes S-phase arrest, cell proliferation and aggressive oncogenic potential (41-43). Loss-of-function of the SKPCullin, F-box containing complex (SCF)/SKP2 and degradation of the cyclin inhibitor $\mathrm{p} 27^{\mathrm{KIP} 1}$ appear to be controlling factors in migration, inadequate growth arrest and invasion of diverse cancer types $(42,44)$. Recent work indicated that activated CDK2 and several of the polo-like kinases collaborate to phosphorylate $G_{2}$ checkpoint kinase (WEE1), which could promote its ubiquitination by SCF (beta-transducing repeat containing (beta-TRCP) and in this manner perpetuate feedback signals to reinforce cycle transition (45).

TSA also reduced transcripts of the cell division cycle protein 45 (CDC45), which is required for DNA synthesis during genome duplication. CDC45 is overexpressed in several types of tumor cell, where it responsible for sustaining rapid rounds of cell division, amplification of DNA replication, chromosomal loading and unwinding and DNA synthesis at the replication fork (46). These events then activate CDKs and Dbf4-dependent kinase (DDK) to allow continued binding of CDC45 and heterotetramer of Sld5, Psf1, Psf2, and Psf3 (GINS) required for the CDC45/MCM27/GINS complex, and initiation/elongation of DNA for replication by DNA polymerase $(47,48)$. Furthermore, TSA rendered considerable loss of expression of $C D K 4$, endothelial differentiation-related factor $1(E D F 1)$ and $E D F 3$, all of which play critical roles in the cell cycle at the $\mathrm{G}_{1} / \mathrm{S}$ transition. CDK4 normally phosphorylates retinoblastoma protein $(\mathrm{Rb})(49)$ causing its disassociation from E2F transcription factor, where E2F is then free to transcribe S-phase-promoting genes. Normally the Rb tumor suppressor restrains the cell cycle by binding E2F1, rendering its inability to transcribe E2F genes that encode many proteins involved with DNA replication. Downregulation of CKD4 could leave more unphosphorylated $\mathrm{Rb}$, and therefore halt the cell cycle at this point. Several studies show this where knockdown of $C D K 4$ or use of compounds that are involved with its reduction such as asiatic acid will induce $G_{0} / G_{1}$ phase arrest of the cells $(49,50)$. Alterations in any key target of the $\mathrm{CDK}-\mathrm{Rb}$ machinery will disrupt cell-cycle regulation, this being a valuable target for chemotherapeutic drug development.

Apoptosis. While TSA itself has been reported to induce apoptosis, cell death was not observed in this study at concentrations where HDAC inhibition occurred $(51,52)$. In contrast, we found confounding evidence of opposing forces in apoptosis, with significant losses of both tumor suppressor (TP53) and oncogenes (BCL2). While we confirm the work of others in the loss of BCL2 commonly reported with HDAC inhibitors $(51,53)$, we also confirm the less-reported attenuation of p53 (20). In general, it appears that HDAC inhibitors mediate anti-mitotic effects which predominate at a lower concentration over apoptotic effects.

Carbonic anhydrase. New findings in this work show that TSA induced a large loss in carbonic anhydrase 14 (CAXIV; 10-fold change, $p<0.0001$ ). Human carbonic anhydrases (EC 4.2.1.1) types IX and XII are overexpressed in a variety of cancer types and play a large role in $\mathrm{pH}$ regulation required to drive metastasis and growth, with greater importance to solid hypoxic tumors (54). Drugs such as CAIX inhibitor FC16-670A or any other compound that can down-regulate carbonic anhydrases will inevitably reduce the capacity of tumor cells to maintain acid-base equilibrium and thereby deal a vital blow to cancer survival, growth and resistance (e.g., sulfamides (acetazolamide) and coumarins (umbelliferon)) $(55,56)$. Combined efficacy of chemotherapy drug treatment is greater when combined with an inhibitor of carbonic acids, proton pumps (57), or HDACs (58), all of which could reduce tumor acidity.

Tetraspanin 13. Here we report the TSA-mediated up-regulation of tetraspanin 13 (TSP13; 27.1-fold change, $p<0.0001)$, the ramifications of which have not been subject to much research. Sparse research on its role shows TSP13 to be a diagnostic marker for prostate cancer (59), where its expression is inversely correlated to Gleason score $(p=0.01)$, and high levels correlate with favorable prognosis (60). The role of TSP13 in the oncogenic potential of melanoma will require further investigation.

\section{Conclusion}

This work provides a basic framework showing global transcriptomic changes using a pan-HDAC inhibitor in $B R A F$-mutant melanoma. The data provide evidence that 

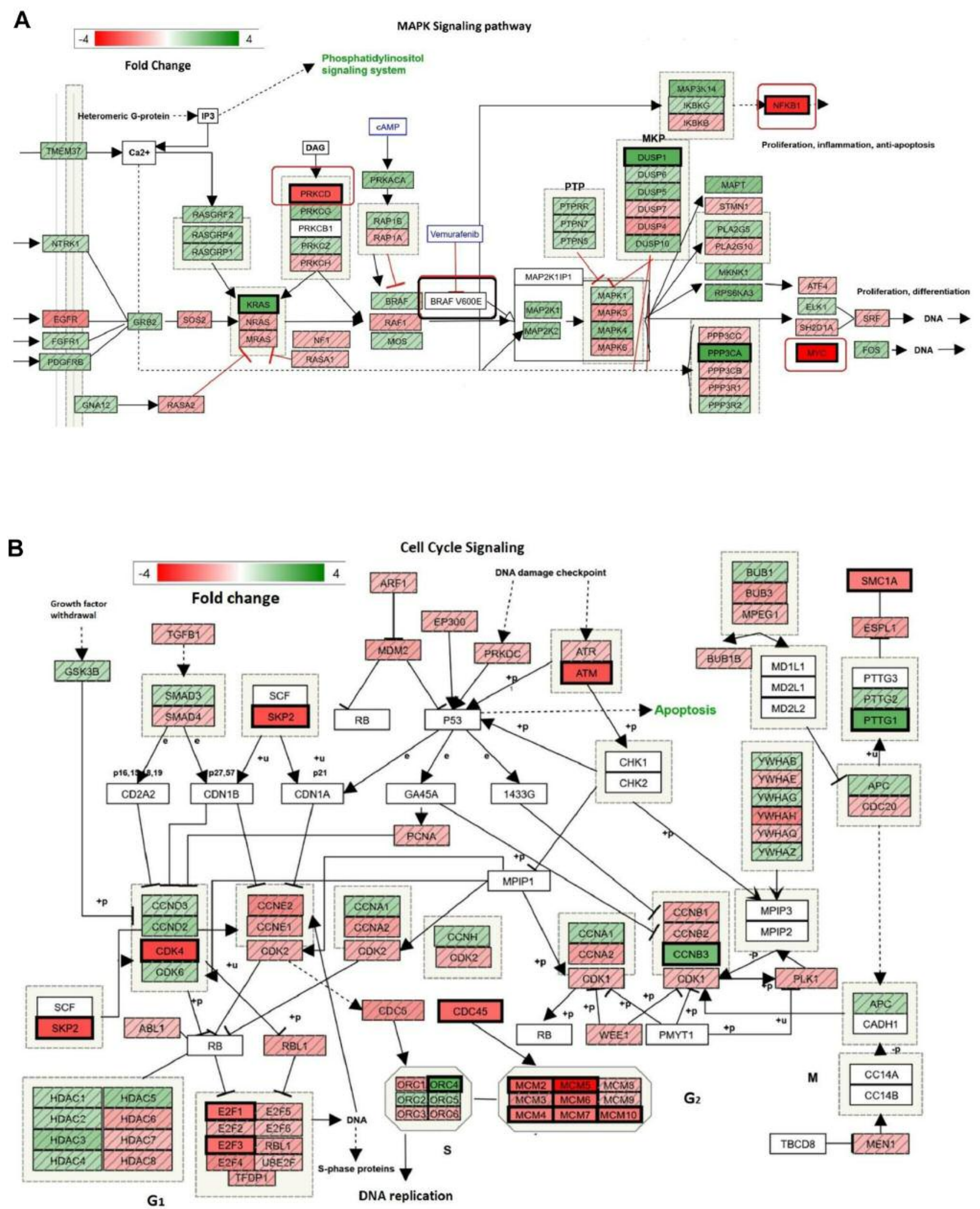

Figure 6. Continued 

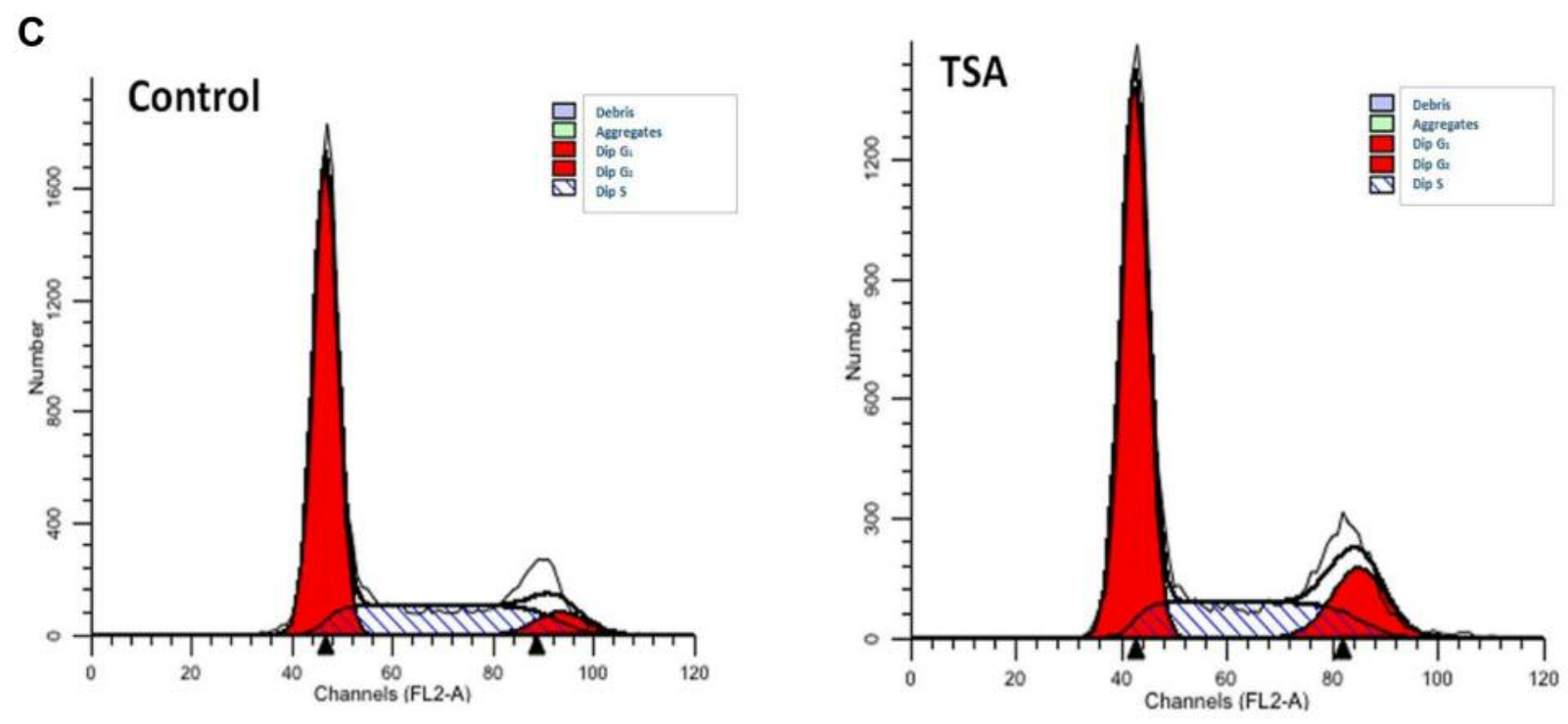

D

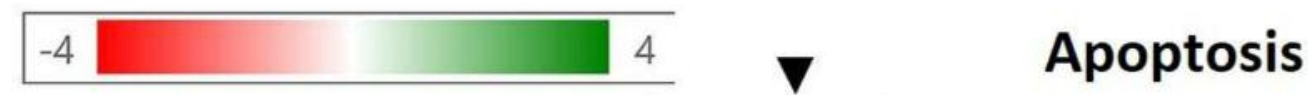

\section{Fold change}

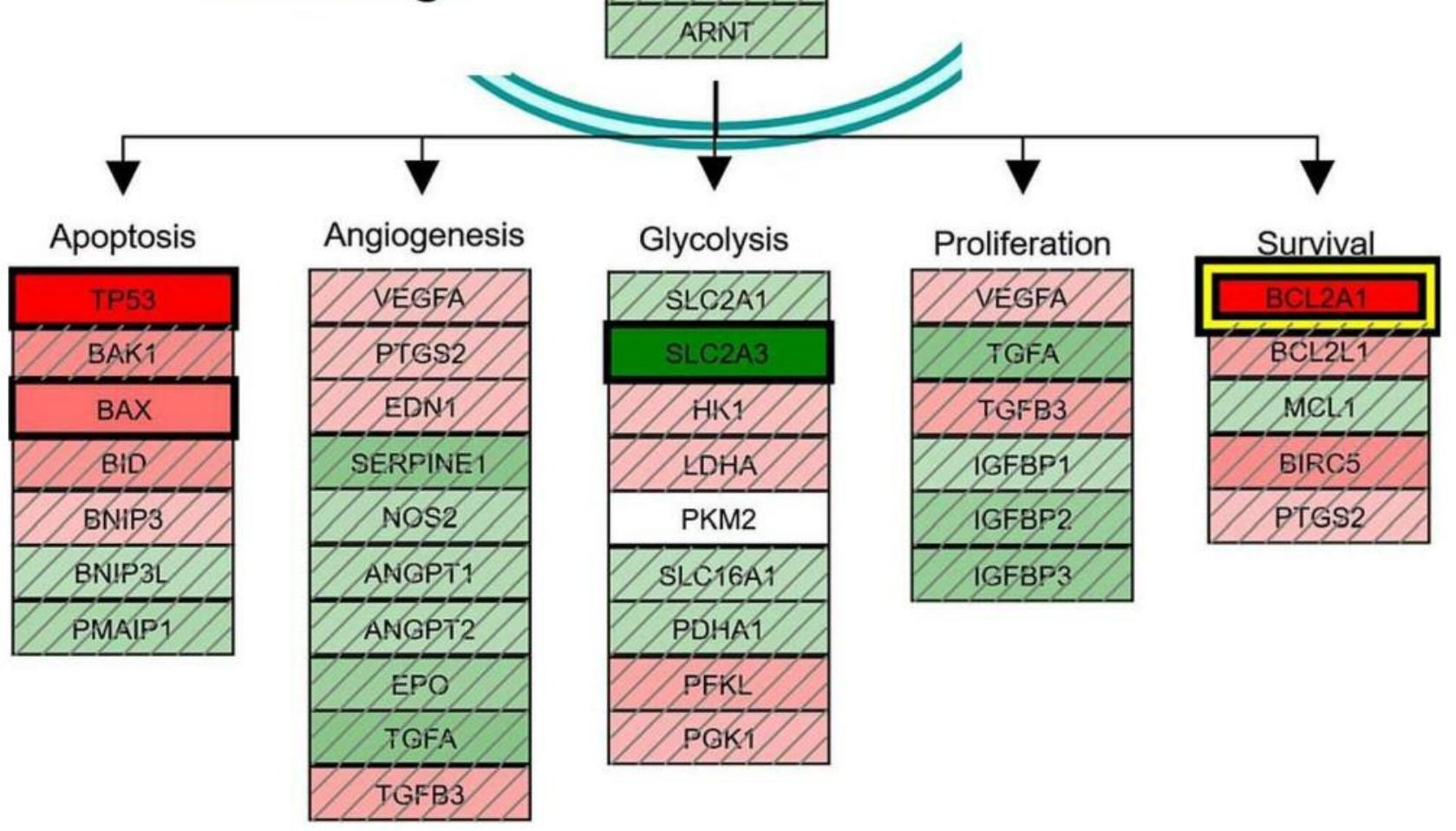

Figure 6. Pathway analysis. Effects of histone deacetylase (HDAC) enzyme inhibition with trichostatin A (TSA) (1 $\mu$ M) at 24 h on A: Mitogenactivated protein kinases (MAPK) signaling, B: cell-cycle signaling, C: cell-cycle distribution, and D: apoptosis. In C, representative cytograms are shown in the upper two panels; in the lower panel, the data represent the mean percentage of cells per phase ( \pm SEM; $n=4)$, and significance of differences from controls was determined with a t-test. *Significantly different at $p<0.05$. 
TSA while inhibiting HDAC enzyme activity, does not alter transcription of various classes of HDAC nor BRAF itself, but in fact down-regulates critical components of MAPKMEK-/BRAF oncogenic pathways, initiating a mitotic arrest. Functional pathway analysis showed that TSA negatively affected cell cycle progression, with flow cytometry confirming a halt at the $G_{2}$ phase with no effect on apoptosis. The loss of anti-apoptotic $B C L 2$ juxtaposed on the loss of apoptotic TP53 may account for the lack of toxicity observed in TSA-treated cells. These data provide a basis for further investigation as to the mechanisms of action for HDAC inhibition in $B R A F$-mutant malignant melanoma.

\section{Data Sharing}

The data discussed in this publication have been deposited in NCBI's Gene Expression Omnibus and are accessible through GEO Series accession number GSE102891 LOCATED AT https:// www.ncbi.nlm.nih.gov/geo/query/acc.cgi?acc=GSE104265

\section{Conflicts of Interest}

The Authors confirm that there are no known conflicts of interest associated with this publication and there was no significant financial support for this work that could have influenced its outcome.

\section{Acknowledgements}

This project was supported by grants from the National Institutes of Health, National Institute on Minority Health and Health Disparities, RCMI grant (G12MD007582), COE grant (P20 MD006738) and the National Cancer Institute under grant number P50 CA168536, Moffitt Skin Cancer SPORE, CEP Program. The Authors would like to thank Dr. Ramesh Badisa, from Florida A \& M University, College of Pharmacy and Pharmaceutical Sciences for his support in flow cytometry data acquisition and analysis.

\section{References}

1 Reifenberger J, Knobbe CB, Sterzinger AA, Blaschke B, Schulte KW, Ruzicka T and Reifenberger G: Frequent alterations of Ras signaling pathway genes in sporadic malignant melanomas. Int J Cancer 109: 377-384, 2004.

2 Lito P, Pratilas CA, Joseph EW, Tadi M, Halilovic E, Zubrowski M, Huang A, Wong WL, Callahan MK, Merghoub T, Wolchok JD, de Stanchina E, Chandarlapaty S, Poulikakos PI, Fagin JA and Rosen N: Relief of profound feedback inhibition of mitogenic signaling by RAF inhibitors attenuates their activity in BRAFV600E melanomas. Cancer Cell 22: 668-682, 2012.

3 Davies H, Bignell GR, Cox C, Stephens P, Edkins S, Clegg S, Teague J, Woffendin H, Garnett MJ, Bottomley W, Davis N, Dicks E, Ewing R, Floyd Y, Gray K, Hall S, Hawes R, Hughes J, Kosmidou V, Menzies A, Mould C, Parker A, Stevens C, Watt S, Hooper S, Wilson R, Jayatilake H, Gusterson BA, Cooper C, Shipley J, Hargrave D, Pritchard-Jones K, Maitland N, Chenevix-Trench G, Riggins GJ, Bigner DD, Palmieri G, Cossu A, Flanagan A, Nicholson A, Ho JW, Leung SY, Yuen ST, Weber
BL, Seigler HF, Darrow TL, Paterson H, Marais R, Marshall CJ, Wooster R, Stratton MR and Futreal PA: Mutations of the BRAF gene in human cancer. Nature 417: 949-954, 2002.

4 Calipel A, Lefevre G, Pouponnot C, Mouriaux F, Eychene A and Mascarelli F: Mutation of $B R A F$ in human choroidal melanoma cells mediates cell proliferation and transformation through the MEK/ERK pathway. J Biol Chem 278: 42409-42418, 2003.

5 Manzano JL, Layos L, Buges C, de Los Llanos Gil M, Vila L, Martinez-Balibrea E and Martinez-Cardus A: Resistant mechanisms to BRAF inhibitors in melanoma. Ann Transl Med 4: 237, 2016.

6 Wahid M, Jawed A, Mandal RK, Dar SA, Akhter N, Somvanshi P, Khan F, Lohani M, Areeshi MY and Haque S: Recent developments and obstacles in the treatment of melanoma with BRAF and MEK inhibitors. Crit Rev Oncol Hematol 125: 8488, 2018.

7 Le K, Blomain ES, Rodeck U and Aplin AE: Selective RAF inhibitor impairs ERK1/2 phosphorylation and growth in mutant NRAS, vemurafenib-resistant melanoma cells. Pigment Cell Melanoma Res 26: 509-517, 2013.

8 Johnson DB, Childress MA, Chalmers ZR, Frampton GM, Ali SM, Rubinstein SM, Fabrizio D, Ross JS, Balasubramanian S, Miller VA, Stephens PJ, Sosman JA and Lovly CM: BRAF internal deletions and resistance to BRAF/MEK inhibitor therapy. Pigment Cell Melanoma Res 31: 432-436, 2018.

9 Tran KA, Cheng MY, Mitra A, Ogawa H, Shi VY, Olney LP, Kloxin AM and Maverakis E: MEK inhibitors and their potential in the treatment of advanced melanoma: the advantages of combination therapy. Drug Des Devel Ther 10: 43-52, 2016.

10 Mazzio EA and Soliman KF: Basic concepts of epigenetics: The impact of environmental signals on gene expression. Epigenetics 7: 119-130, 2012.

11 Gallagher SJ, Tiffen JC and Hersey P: Histone modifications, modifiers, and readers in melanoma resistance to targeted and immune therapy. Cancers (Basel) 7: 1959-1982, 2015.

12 Krumm A, Barckhausen C, Kucuk P, Tomaszowski KH, Loquai C, Fahrer J, Kramer OH, Kaina B and Roos WP: Enhanced histone deacetylase activity in malignant melanoma provokes RAD51 and FANCD2-triggered drug Resistance. Cancer Res 76: 3067-3077, 2016.

13 Hornig E, Heppt MV, Graf SA, Ruzicka T and Berking C: Inhibition of histone deacetylases in melanoma-a perspective from bench to bedside. Exp Dermatol 25: 831-838, 2016.

14 Jonas O, Oudin MJ, Kosciuk T, Whitman M, Gertler FB, Cima MJ, Flaherty KT and Langer R: Parallel in vivo assessment of drug phenotypes at various time points during systemic BRAF inhibition reveals tumor adaptation and altered treatment vulnerabilities. Clin Cancer Res 22: 6031-6038, 2016.

15 Lai F, Guo ST, Jin L, Jiang CC, Wang CY, Croft A, Chi MN, Tseng HY, Farrelly M, Atmadibrata B, Norman J, Liu T, Hersey $\mathrm{P}$ and Zhang XD: Cotargeting histone deacetylases and oncogenic BRAF synergistically kill human melanoma cells by necrosis independently of RIPK1 and RIPK3. Cell Death Dis 4: e655, 2013.

16 Wilmott JS, Colebatch AJ, Kakavand H, Shang P, Carlino MS, Thompson JF, Long GV, Scolyer RA and Hersey P: Expression of the class 1 histone deacetylases HDAC 8 and 3 are associated with improved survival of patients with metastatic melanoma. Mod Pathol 28: 884-894, 2015. 
17 Dai W, Zhou J, Jin B and Pan J: Class III-specific HDAC inhibitor Tenovin-6 induces apoptosis, suppresses migration and eliminates cancer stem cells in uveal melanoma. Sci Rep 6: 22622, 2016.

18 Venza I, Visalli M, Oteri R, Teti D and Venza M: Class I-specific histone deacetylase inhibitor MS-275 overrides TRAILresistance in melanoma cells by downregulating c-FLIP. Int Immunopharmacol 21: 439-446, 2014.

19 Huang da W, Sherman BT and Lempicki RA: Bioinformatics enrichment tools: paths toward the comprehensive functional analysis of large gene lists. Nucleic Acids Res 37: 1-13, 2009.

20 Garmpis N, Damaskos C, Garmpi A, Dimitroulis D, Spartalis E, Margonis GA, Schizas D, Deskou I, Doula C, Magkouti E, Andreatos N, Antoniou EA, Nonni A, Kontzoglou K and Mantas D: Targeting histone deacetylases in malignant melanoma: A future therapeutic agent or just great expectations? Anticancer Res 37: 5355-5362, 2017.

21 Ibrahim N, Buchbinder EI, Granter SR, Rodig SJ, GiobbieHurder A, Becerra C, Tsiaras A, Gjini E, Fisher DE and Hodi FS: A phase I trial of panobinostat (LBH589) in patients with metastatic melanoma. Cancer Med 5: 3041-3050, 2016.

22 Yao L, Wang L, Li F, Gao X, Wei X and Liu Z: MiR181c inhibits ovarian cancer metastasis and progression by targeting PRKCD expression. Int J Clin Exp Med 8: 15198-15205, 2015.

23 Abe Y, Nagano M, Kuga T, Tada A, Isoyama J, Adachi J and Tomonaga T: Deep phospho-and phosphotyrosine proteomics identified active kinases and phosphorylation networks in colorectal cancer cell lines resistant to cetuximab. Sci Rep 7: 10463, 2017.

24 Zuo Y, Wu Y and Chakraborty C: CDC42 negatively regulates intrinsic migration of highly aggressive breast cancer cells. J Cell Physiol 227: 1399-1407, 2012.

25 Chauvin L, Goupille C, Blanc C, Pinault M, Domingo I, Guimaraes C, Bougnoux P, Chevalier S and Maheo K: Long chain n-3 polyunsaturated fatty acids increase the efficacy of docetaxel in mammary cancer cells by down-regulating AKT and PKCepsilon/delta-induced ERK pathways. Biochim Biophys Acta 1861: 380-390, 2016.

26 Chen CL, Wang SH, Chan PC, Shen MR and Chen HC: Phosphorylation of E-cadherin at threonine 790 by protein kinase Cdelta reduces beta-catenin binding and suppresses the function of E-cadherin. Oncotarget 7: 37260-37276, 2016.

$27 \mathrm{Kim} \mathrm{H}, \mathrm{Na}$ YR, Kim SY and Yang EG: Protein kinase C isoforms differentially regulate hypoxia-inducible factor-1alpha accumulation in cancer cells. J Cell Biochem 117: 647-658, 2016.

28 Zhu S, Yao F, Li WH, Wan JN, Zhang YM, Tang Z, Khan S, Wang $\mathrm{CH}$ and Sun SR: PKCD-dependent activation of the ubiquitin proteasome system is responsible for high glucoseinduced human breast cancer MCF-7 cell proliferation, migration, and invasion. Asian Pac J Cancer Prev 14: $5687-$ 5692, 2013.

29 Singleton KR, Crawford L, Tsui E, Manchester HE, Maertens O, Liu X, Liberti MV, Magpusao AN, Stein EM, Tingley JP, Frederick DT, Boland GM, Flaherty KT, McCall SJ, Krepler C, Sproesser K, Herlyn M, Adams DJ, Locasale JW, Cichowski K, Mukherjee S and Wood KC: Melanoma therapeutic strategies that select against resistance by exploiting MYC-driven evolutionary convergence. Cell Rep 21: 2796-2812, 2017.

30 Kfoury A, Armaro M, Collodet C, Sordet-Dessimoz J, Giner MP, Christen S, Moco S, Leleu M, de Leval L, Koch U, Trumpp A,
Sakamoto K, Beermann F and Radtke F: AMPK promotes survival of c-MYC-positive melanoma cells by suppressing oxidative stress. EMBO J 37(5), 2018. doi: 10.15252/embj.201797673.

31 Korkut A, Wang W, Demir E, Aksoy BA, Jing X, Molinelli EJ, Babur O, Bemis DL, Onur Sumer S, Solit DB, Pratilas CA and Sander C: Perturbation biology nominates upstream-downstream drug combinations in RAF inhibitor resistant melanoma cells. Elife 4, 2015. doi: 10.7554/eLife.04640.

32 Liu D, Liu X and Xing M: Activities of multiple cancer-related pathways are associated with $B R A F$ mutation and predict the resistance to BRAF/MEK inhibitors in melanoma cells. Cell Cycle 13: 208-219, 2014.

$33 \mathrm{Qu}$ X, Shen L, Zheng Y, Cui Y, Feng Z, Liu F and Liu J: A signal transduction pathway from TGF-beta1 to SKP2 via AKT1 and c-MYC and its correlation with progression in human melanoma. J Invest Dermatol 134: 159-167, 2014.

34 Mahapatra L, Andruska N, Mao C, Le J and Shapiro DJ: A novel IMP1 inhibitor, BTYNB, targets c-MYC and inhibits melanoma and ovarian cancer cell proliferation. Transl Oncol 10: 818-827, 2017.

35 Chen Y, Bathula SR, Yang Q and Huang L: Targeted nanoparticles deliver siRNA to melanoma. J Invest Dermatol 130: 2790-2798, 2010.

36 Dorasamy MS, Choudhary B, Nellore K, Subramanya H and Wong PF: Dihydroorotate dehydrogenase inhibitors target cMYC and arrest melanoma, myeloma and lymphoma cells at Sphase. J Cancer 8: 3086-3098, 2017.

37 Zhang F, Shen M, Yang L, Yang X, Tsai Y, Keng PC, Chen Y, Lee SO and Chen Y: Simultaneous targeting of ATM and MCL1 increases cisplatin sensitivity of cisplatin-resistant non-small cell lung cancer. Cancer Biol Ther 18: 606-615, 2017.

38 Stolz A, Ertych N and Bastians H: Tumor suppressor CHK2: A regulator of DNA damage response and mediator of chromosomal stability. Clin Cancer Res 17: 401-405, 2011.

39 Squatrito M, Brennan CW, Helmy K, Huse JT, Petrini JH and Holland EC: Loss of ATM/CHK2/p53 pathway components accelerates tumor development and contributes to radiation resistance in gliomas. Cancer Cell 18: 619-629, 2010.

40 Wang W, Nacusi L, Sheaff RJ and Liu X: Ubiquitination of P21CIP1/WAF1 by SCFSKP2: substrate requirement and ubiquitination site selection. Biochemistry 44: 14553-14564, 2005.

41 Gstaiger M, Jordan R, Lim M, Catzavelos C, Mestan J, Slingerland $J$ and Krek W: SKP2 is oncogenic and overexpressed in human cancers. Proc Natl Acad Sci USA 98: 5043-5048, 2001.

42 Li P, Li C, Zhao X, Zhang X, Nicosia SV and Bai W: p27(KIP1) stabilization and $\mathrm{G}(1)$ arrest by 1,25-dihydroxyvitamin $\mathrm{D}(3)$ in ovarian cancer cells mediated through down-regulation of cyclin E/cyclin-dependent kinase 2 and SKP1-Cullin-F-box protein/ SKP2 ubiquitin ligase. J Biol Chem 279: 25260-25267, 2004.

43 Bornstein G, Bloom J, Sitry-Shevah D, Nakayama K, Pagano M and Hershko A: Role of the SCFSKP2 ubiquitin ligase in the degradation of P21CIP1 in S phase. J Biol Chem 278: 2575225757, 2003.

44 Nakamura Y, Ozaki T, Koseki H, Nakagawara A and Sakiyama S: Accumulation of p27 KIP1 is associated with BMP2-induced growth arrest and neuronal differentiation of human neuroblastoma-derived cell lines. Biochem Biophys Res Commun 307: 206-213, 2003. 
45 Ang XL and Harper JW: Interwoven ubiquitination oscillators and control of cell cycle transitions. Sci STKE 2004: pe31, 2004.

46 Sun J, Shi R, Zhao S, Li X, Lu S, Bu H and Ma X: Cell division cycle 45 promotes papillary thyroid cancer progression via regulating the cell cycle. Tumour Biol 39: 1010428317705342, 2017.

$47 \mathrm{Xu}$ Y, Gristwood T, Hodgson B, Trinidad JC, Albers SV and Bell SD: Archaeal orthologs of Cdc45 and GINS form a stable complex that stimulates the helicase activity of MCM. Proc Natl Acad Sci USA 113: 13390-13395, 2016.

48 Yabuuchi H, Yamada Y, Uchida T, Sunathvanichkul T, Nakagawa $\mathrm{T}$ and Masukata H: Ordered assembly of SLD3, GINS, and CDC45 is distinctly regulated by DDK and CDK for activation of replication origins. EMBO J 25: 4663-4674, 2006.

49 Chen H, Xu X, Wang G, Zhang B, Wang G, Xin G, Liu J, Jiang $\mathrm{Q}$, Zhang $\mathrm{H}$ and Zhang $\mathrm{C}$ : CDK4 protein is degraded by anaphase-promoting complex/cyclosome in mitosis and reaccumulates in early $\mathrm{G} 1$ phase to initiate a new cell cycle in HeLa cells. J Biol Chem 292: 10131-10141, 2017.

50 Jing Y, Wang G, Ge Y, Xu M, Tang S and Gong Z: AA-PMe, a novel asiatic acid derivative, induces apoptosis and suppresses proliferation, migration, and invasion of gastric cancer cells. Onco Targets Ther 9: 1605-1621, 2016.

51 Choi YH: Induction of apoptosis by trichostatin A, a histone deacetylase inhibitor, is associated with inhibition of cyclooxygenase-2 activity in human non-small cell lung cancer cells. Int J Oncol 27: 473-479, 2005.

52 Vanhaecke T, Henkens T, Kass GE and Rogiers V: Effect of the histone deacetylase inhibitor trichostatin $\mathrm{A}$ on spontaneous apoptosis in various types of adult rat hepatocyte cultures. Biochem Pharmacol 68: 753-760, 2004.

53 Duan H, Heckman CA and Boxer LM: Histone deacetylase inhibitors down-regulate BCL-2 expression and induce apoptosis in $\mathrm{t}(14 ; 18)$ lymphomas. Mol Cell Biol 25: 1608-1619, 2005.

54 Ansari MF, Idrees D, Hassan MI, Ahmad K, Avecilla F and Azam A: Design, synthesis and biological evaluation of novel pyridine-thiazolidinone derivatives as anticancer agents: Targeting human carbonic anhydrase IX. Eur J Med Chem 144: 544-556, 2018.
55 Queen A, Khan P, Idrees D, Azam A and Hassan MI: Biological evaluation of p-toluene sulphonylhydrazone as carbonic anhydrase IX inhibitors: An approach to fight hypoxia-induced tumors. Int J Biol Macromol 106: 840-850, 2018.

56 Puech C, Chatard M, Felder-Flesch D, Prevot N and Perek N: Umbelliferone decreases intracellular $\mathrm{pH}$ and sensitizes melanoma cell line A375 to dacarbazin. Comparison with acetazolamide. Curr Mol Pharmacol 11(2): 133-139, 2016.

57 Federici C, Lugini L, Marino ML, Carta F, Iessi E, Azzarito T, Supuran CT and Fais S: Lansoprazole and carbonic anhydrase IX inhibitors sinergize against human melanoma cells. J Enzyme Inhib Med Chem 31: 119-125, 2016.

58 Bayat Mokhtari R, Baluch N, Ka Hon Tsui M, Kumar S, T SH, Aitken K, Das B, Baruchel S and Yeger H: Acetazolamide potentiates the anti-tumor potential of HDACi, MS-275, in neuroblastoma. BMC Cancer 17: 156, 2017.

59 Yan C, Kim YH, Kang HW, Seo SP, Jeong P, Lee IS, Kim D, Kim JM, Choi YH, Moon SK, Yun SJ and Kim WJ: Urinary nucleic acid TSPAN13-to-S100A9 ratio as a diagnostic marker in prostate cancer. J Korean Med Sci 30: 1784-1792, 2015.

60 Arencibia JM, Martin S, Perez-Rodriguez FJ and Bonnin A: Gene expression profiling reveals overexpression of TSPAN13 in prostate cancer. Int J Oncol 34: 457-463, 2009.

$61 \mathrm{Mi} \mathrm{H}$, Muruganujan A and Thomas PD: PANTHER in 2013: Modeling the evolution of gene function, and other gene attributes, in the context of phylogenetic trees. Nucleic Acids Res 41: D377-386, 2013.

62 Gaudet P, Livstone MS, Lewis SE and Thomas PD: Phylogenetic-based propagation of functional annotations within the Gene Ontology consortium. Brief Bioinform 12: 449-462, 2011.
Received June 8, 2018

Revised July 9, 2018

Accepted July 16, 2018 